\title{
Navigating the ethical quandaries of wraparound multi -systemic treatment (MST): A comparative study between in -home and outpatient therapies
}

Joseph M. Roberts

West Virginia University

Follow this and additional works at: https://researchrepository.wvu.edu/etd

\section{Recommended Citation}

Roberts, Joseph M., "Navigating the ethical quandaries of wraparound multi -systemic treatment (MST): A comparative study between in -home and outpatient therapies" (2006). Graduate Theses, Dissertations, and Problem Reports. 2512.

https://researchrepository.wvu.edu/etd/2512

This Dissertation is protected by copyright and/or related rights. It has been brought to you by the The Research Repository @ WVU with permission from the rights-holder(s). You are free to use this Dissertation in any way that is permitted by the copyright and related rights legislation that applies to your use. For other uses you must obtain permission from the rights-holder(s) directly, unless additional rights are indicated by a Creative Commons license in the record and/ or on the work itself. This Dissertation has been accepted for inclusion in WVU Graduate Theses, Dissertations, and Problem Reports collection by an authorized administrator of The Research Repository @ WVU.

For more information, please contact researchrepository@mail.wvu.edu. 
Navigating the Ethical Quandaries of Wraparound Multi-Systemic Treatment (MST): A Comparative Study Between In-Home and Outpatient Therapies

Joseph M. Roberts

Dissertation submitted to the College of Human Resources and Education at West Virginia University in partial fulfillment of the requirements for the degree of

Doctor of Philosophy in

Counseling Psychology

Roy Tunick, Ed.D., Chair

Jennifer Adams, Ph.D.

William Fremouw, Ph.D.

D.J. Hendricks, Ph.D. Ed Jacobs, Ph.D.

Department of Counseling Psychology

Morgantown, West Virginia 2006

Keywords: Wraparound, In-Home Therapy, Ethics

Copyright 2006 Joseph M. Roberts 


\title{
ABSTRACT \\ Navigating the Ethical Quandaries of Multi-Systemic Treatment (MST): A Comparative Study Between In-Home and Outpatient Therapies
}

\author{
Joseph M. Roberts
}

Multisystemic treatments (MST) have become a significant force in the mental health community over the past decade. Yet, scant literature is available in regards to differing ethical considerations that may arise when working outside of a traditional office setting. The current research reviewed key ethical issues within the therapeutic relationship (i.e., confidentiality, dual roles), and extended the discussion to pertinent, often unrecognized issues endemic to in-home service modalities (i.e., confidentiality, role confusion, client diffusion, and unintentional witnessing).

More specifically, this research examined whether certain ethical violations are perceived to occur less frequently in outpatient settings compared to in-home settings. It was hypothesized that in-home therapists would report more possible hypothetical experiences with these kinds of violations than their outpatient therapist counterparts. A survey was mailed to agencies that employ both outpatient and in-home therapists in the states of Pennsylvania and Eastern Ohio to test this hypothesis. The therapists had a minimum educational level of a Master's degree.

The study examines those therapists that worked with children under the age of eighteen, using in-home or multisystemic therapy (MST). Likewise, office-based therapists who treated the same age-group were sought to offer balance for data interpretation. Hence, the comparison between office-based and in-home therapist's ethical dilemmas were the primary focus.

Ninety-seven therapists completed the survey and some of the results showed significant differences in both ethical perceptions and supervision standards. In-home therapists noted significantly higher perceived instances of confidentiality $(\mathrm{p}=.003)$ and role confusion $(\mathrm{p}=.04)$ ethical quandaries than their office-based colleagues. In addition, in-home therapists stated that they received significantly less individual supervision $(\mathrm{p}=.01)$ than office-based therapists, used clinical consultation less frequently $(\mathrm{p}=.01)$ and were more likely to withhold information from their direct supervisors $(\mathrm{p}=.03)$. Years worked in the field, state licensure, and whether or not a therapist had taken an ethics course did not appear to be significant in terms of observing ethical dilemmas in their work. 


\section{Acknowledgements \& Dedication}

I am grateful to Robert P. Marinelli, Ed.D. for his initial guidance in directing me toward ethical studies. I am also indebted to Roy Tunick, Ed.D. for becoming the chair of this dissertation during a complicated time in its completion. I appreciate the input that I have been given by the other members of my committee and am thankful that Jennifer Adams, Ph.D. was kind enough to fill the void left by the retired Dr. Marinelli.

I am additionally thankful to my longtime friend and therapeutic sensei, David Mente, who facilitated the distribution of the many surveys that were disseminated in the Pittsburgh area to local wraparound and outpatient agencies. I appreciate the therapists who participated in this survey for their investment of time and their words of encouragement.

Specifically, I would like to thank my wife, Jen, who not only gave me continued guidance and support during the long-road toward attaining this degree, but who also offered me calming words and tasty oven-rice whenever the task seemed insurmountable. I also thank my brother, Sean, for the occasional pint and discourse on topics nonpsychological in nature, my mother, Ann Marie, who logged countless hours watching my daughter, and my father, Joe, who always told me to “follow my bliss".

Lastly, I dedicate this to the keystone of my life, my beautiful daughter, Mackenna. I hope that I may one day be fortunate enough to grace her acknowledgements page. 
Table of Contents

Abstract

$\underline{\text { Page }}$

Acknowledgments

ii

Table of Contents

iv

Chapter 1: Introduction and Literature Review 1

The Rise of Multisystemic Treatments 2

Ethics and the Modern Psychologist 5

Supervision and Practice $\quad 7$

Special Ethical Concerns with Wraparound Therapy (MST) 11

$\begin{array}{ll}\text { Confidentiality } & 12 \\ & 15\end{array}$

Role Confusion $\quad 15$

Client Diffusion $\quad 21$

Unintentional Witnessing 23

Statement of the Problem 28

Purpose of the Study $\quad 30$

Research Questions $\quad 32$

Chapter 2: Methodology $\quad 35$

Participants $\quad 35$

Operational Definitions $\quad 39$

Survey $\quad 40$

General Discussion $\quad 41$

Specific Items 41

Discussion of Survey Administration 42

Research Design and Analysis Plan $\quad 44$

Chapter 3: Results $\quad 48$

Confidentiality 49

Role Confusion $\quad 50$

Client Diffusion $\quad 50$

Unintentional Witnessing $\quad 51$

Tests of Research Questions $\quad 51$

Regression Models $\quad 56$

Chapter 4: Discussion, Limitations, and Future Directions of the Study 58

Summary of the Study 58

Discussion and Implication of Research Findings $\quad 59$

Research Question One $\quad 59$

Research Question Two 59

Research Question Three $\quad 60$

Research Question Four 61

Research Question Five $\quad 62$

Comments on the Survey 63

Limitations 65 
$\begin{array}{ll}\text { References } & 70\end{array}$

$\begin{array}{ll}\text { Appendix A } & 77\end{array}$

$\begin{array}{ll}\text { Survey Instrument } & 77\end{array}$

Appendix B

Table $1 \quad$ Demographics $\quad 85$

Table 2 Reliability Analysis of Confidentiality Measure 88

Table $3 \quad$ Reliability Analysis of Confusion Measure 89

Table $4 \quad$ Reliability Analysis of Client Diffusion Measure 90

Table $5 \quad$ Reliability Analysis of Unintentional Witnessing 91

Measure

Table $6 \quad$ Hypothesis \#1: Independent Sample Difference of 92

Means Test for Completing an Ethics course and the

4 Ethical Dimensions

Table $7 \quad$ Hypothesis \#2: Independent Sample Difference of 93

Means Test for State Licensure and the

4 Ethical Dimensions

Table 8 Hypothesis \#3: Independent Sample Difference of 94

Means Test for Amount of Structured Supervision

And Type of Therapist

Table 9 Hypothesis \#4: One Way Analysis of Variance

Between Years Working as a Therapist and 4

Ethical Dimensions

Table 10 Hypothesis \#5: Independent Sample Difference of 96

Means Test Between Type of Therapist and 4

Ethical Dimensions

Table 11 Hypothesis \#5: Independent Difference of Means 97

Between Type of Therapist and Demographics

Table 12 Hypothesis \#5: Ordinary Least Squares Regression of 98 Confidentiality Scale

Table 13 Hypothesis \#5: Ordinary Least Squares Regression of 98

Table $14 \quad$ Hypothesis \#5: Ordinary Least Squares Regression of 99

Client Diffusion Scale

Table $15 \quad$ Hypothesis \#5: Ordinary Least Squares Regression of 99 Unintentional Witnessing Scale

Appendix C

Resume 


\section{CHAPTER ONE INTRODUCTION \& LITERATURE REVIEW}

This chapter provides an introduction to this study and its research questions, and explains the structure of the document. A brief statement of the problem is explained and the purpose of the study is described. This chapter also presents a discussion of the relevant literature addressing ethical considerations in multisystemic and outpatient treatments. The chapter is organized in the following fashion: First, a brief discussion of the history and parameters of MST is included to assist in operational definitions and overall concepts that are to be applied. Next, the literature regarding general ethical violations is addressed. Third, current supervisory standards as per the current APA code are addressed to create a context for the purpose of this research. Fourth, specific ethical concerns as related to MST models of therapy are identified and are considered as they relate to this research and the hypothesis in question. Lastly, five research questions are described as they apply to the overall research design.

\section{The Rise of Multisystemic Treatments}

The design of multisystemic treatments (MST) is rooted in both social ecology theory proposed by Bronfenbrenner (1979), as well as growing success obtained through the structural family models of treatment espoused by Minuchin. "Interventions aim to empower parents to facilitate pragmatic changes in the youth's and family's natural environments” (Curtis et al., 2004, p. 411). Family therapy techniques may be the often utilized in this format, but the social-ecology model demands that a therapist extend beyond the primary circle of the family unit and utilize other systems that are in place in 
a child or adolescent's life such as school, peers, church, and community (Henggeler et al., 1998). "MST places a greater emphasis on retaining children in the home and using indigenous supports in the family's ecology to strengthen the parenting subsystem” (Stern, 1999, p. 282). Contemporary problem-solving and reality testing techniques are thought to be successful with MST as many times the clientele exhibit higher rates of oppositionality and anti-social behavior, which are effectively served by these styles of therapy. Empirically validated treatments such as cognitive-behavioral approaches and strategic family therapy are also heavily utilized in the delivery of these services (Stern, 1999).

As of 2002, multisystemic therapy has "been transported to approximately 30 states and 7 nations” (Schoenwald, et al., 2003). MST is regarded as a strong, evidencebased treatment for children and adolescents, and is often regarded as the most significant treatment when dealing with those presenting with oppositional and conduct disordered diagnostic criteria. In a review of the literature from the past decade, Farmer (2004) found that there have been sixteen identified studies of wraparound MST, with results showing relative improvements in living environment permanency, school adjustment, and family stabilization. Others have found that MST is more effective than traditional office-based, outpatient therapy in improving adjustment issues in individual family members, as well as reducing future recidivism in regard to criminal activity (Borduin et al., 1995). Due to the success of wraparound treatments and therapy, treatment providers have led the way toward the utilization of these methods with youth afflicted by more chronic psychiatric problems such as depression, anxiety disorders, bipolar disorder, and psychotic disorders (Farmer, 2004). Recently researchers (Henggeler et al., 2003; \& Schoenwald et al., 2000) examined the impact of MST when compared to inpatient 
hospitalization showed that (at least in preliminary data) that those that were randomized to the MST group (as compared to an inpatient stay) experienced fewer subsequent returns to the hospital, greater attendance in mainstream classrooms, and a greater reduction in the severity of their negative behaviors. It was noted however, that these differences are fleeting as compared to inpatient stay and by the end of a 12-month follow up have shown comparable effects when compared to hospitalization (Farmer, 2004).

MST has continued to gain in popularity with regards to antisocial and delinquent youths largely due to evidence that suggests that this form of therapy has shown a strong combination of treatment success coupled with the retention of a problematic, often reluctant client population (Stern, 1999). Outpatient therapy has notoriously high dropout rates with conduct disordered and oppositional children (as high as 40-60\% according to Kazdin, 1990). In this, in-home therapy show greater promise with these hard-to-reach populations. "MST results are particularly impressive given that the approach focuses on youth with serious clinical problems and multi-stressed families, those least likely to complete or benefit from treatment” (Stern, 1999, p.281).

There are some notable issues in the dissemination of MST with children and adolescents. MST therapists often attempt to increase social involvement with he client's targeted peer group, yet efficacy measures are limited to relationships that may be contrary to continued functioning. Additionally, some researchers have argued that there needs to be an increased understanding of specific mechanisms of change with families under the MST umbrella. Though we are aware that family engagement (Schaffer \& Borduin, 2003), and improved peer relations (Huey, et al., 2000) are important treatment 
mediators, the process by which these mediators of improvement are obtained are often obfuscated (Curtis, Ronan, \& Borduin, 2004).

It would seem that a greater collaboration between existing schemas of family therapy, such as Bowenian and Structural Family Therapy models, would be especially useful if there was a greater impetus on merging MST training of therapists who often come from varied educational backgrounds. Additional concerns arise with in-home therapists, as it tends to engender more temporary employment rather than a professional commitment that evolves into a lengthy career. Those that work within the in-home landscape will often shift to administrative positions within agencies, become traditional office-based therapists, or even leave the field altogether. This phenomenon creates an ever-revolving supply of new therapists to fill the gulf left by their peers in the field. By result, training and continued therapist development may receive less direct attention in order to maintain the overall stability of the delivery system.

Schoenwald et al., (2000) noted the tremendous need for ongoing quality assurance procedures when disseminating MST within community settings, and called attention to the potential gains to be found in these models when compared to traditional outpatient therapy. In a recent study conducted on the overall effectiveness of MST, Curtis et al., (2004) found that across prescribed outcome measures, youth treated with MST showed both higher functioning and reduced criminality when compared to their control group, outpatient peers. Improvements were as high as $70 \%$ when one observed reductions in conduct disordered behaviors in the school and community as the primary outcome measures (p. 413). These intriguing results have been identified by other researchers such as Borduin et al., (1995), who described overall relational deterioration within the target family when the specified adolescent client was the sole target for 
outpatient treatment. This is often accounted for by the organizing tenet that child symptoms may be the acting fulcrum for the family to maintain stabilization through scapegoating and parental joining where the "sick child" can be the focus of reunification between warring parents (Minuchin, 1985).

\section{Ethics and the Modern Therapist}

As there is little research regarding the ethical practices of MST models of therapy, it is prudent to consider research from outside the question, though applicable in many ways. One such area of comparable research in ethics arises from rural models of therapeutic intervention. Roberts et al. (1999) described several areas of ethical concern when working in rural settings that may not be amenable to some of the overall ethical constructs described through the American Psychological Association and supportive research literature. Roberts' outlined five specific areas of ethical concern for rural practitioners, and many of them mirror those experiences faced by in-home, multisystemic therapy. These areas are: 1) overlapping relationships, 2) conflicting roles, 3) therapeutic boundary issues, 4) breaks in confidentiality, and 5) generalist care. Jennings (1992) stated that rural settings create unique issues for ethical concern more out of accessibility as opposed to intentional behaviors by the therapist as is more common in urban areas. When applied to in-home MST, even if within an urban setting as opposed to a rural one, one observes accessibility issues that are more pronounced. Campbell and Gordon (2003) noted that in a rural community, it is impossible to avoid dual relationships with one's clients. An argument can be made that for many of the same reasons, an in-home therapist loses much of the differentiation afforded by a clinical office setting, and in this, is far more approachable as a member of the 
community, rather than as a helping professional. This may be accurate even if the therapist is not a physical neighbor in the community, but is simply seen working there. Pope and Vettor (1994) researched the characteristics of the ethical violators in therapeutic practice, citing that violations generally fall into one of the following types: misinformed type, isolated type, irresponsible type, insensitive type, rationalizing type, slipping type, and vengeful type. The authors stated that rationalizing type was the most common, which is of particular interest to this study, as rationalizing, slipping, and isolated types play to the weaknesses inherent in in-home therapy.

In the most general sense, boundary violations are often cited as the achilles heel to ethical fortitude in a therapist. Researchers such as Lamb and Cutuzarmo (1998), Kitchener and Anderson (2002), and Gottleib et al. (1993), all examine ethical violations from a bottom-top philosophy. All of the above research focuses on those moments when therapists, unaware or unconscious of their motivations, allows their professional role to blur and in doing so opens themselves to legal, professional, and moral hazard. Seemingly innocuous boundary violations have been determined to lead to sexual relationships with clients, which is the primary reason for licensure loss in psychology, social work, and counseling (Vasquez, 1996). Egan and Kadushin (1999) found that social work practice with in-home populations is "more complex and multifaceted than documented in earlier research” (p. 52). Additionally, Gross and Robinson (1987) addressed the importance of the core principles of avoiding dual relationships, conflict of interest situations, and maintaining confidentiality as it applied to licensed counselors. 


\section{Supervision and Practice}

Of central issue to this research is a licensed psychologist who is the primary supervisor for an agency that delivers a combination of office-based and in-home therapy, and whom may have differing expectations or supervisory styles with each kind of therapist. This is a common practice, especially in the non-profit sector where psychologist hours come at a premium. Vasquez (1992) noted the importance of continued supervision to the new psychologist, and indicated that ethics training is an essential component to professional growth, adding: "Perhaps in no other profession but mental health is it as important to promote the professional development of trainees” (p. 199).

As noted by Vasquez (1992), psychologists provide this supervision to a wide array of both employed and student supervisees including interns, practicum students, pre-doctoral and post-doctoral candidates, licensed and unlicensed social workers and professional counselors, and even non-master's level health professionals. Pomerantz et al. (1998) addressed the coalescence of multidisciplinary teams that are often under the direct guidance of an acting psychologist, although the individual members of each professional discipline are guided by similar, but different ethical codes of their professional organizations; codes that may be vague and open to individual interpretation as they relate to not only boundary violations, but to the role of a supervisor and the legal complications that may arise from poor practice or supervision.

A number of researchers have alluded to the complications in addressing ethical differences between therapists that originate from varied training. Lindenthal et al. (1988) indicated that social workers had less stringent practices in regards to

confidentiality when compared to those that were trained from a more clinical, 
psychological perspective. Others such as Bernsen et al. (1994) also found discrepancies between social workers and psychologists doing therapeutic work with clients, noting that social workers often indicated that they considered sexual attraction to be a benefit in therapeutic progress with clients, though they were also more likely to discuss these reactions with their acting supervisor than psychologists. Borys and Pope (1989) found evidence to suggest that psychologists were more rigid in their defining of dual roles when compared to clinical social workers, but then showed some contradictory evidence in that psychologists were more likely to accept small gifts or other tokens of appreciation from clients. Some researchers (Pomerantz et al., 1998; Zadik, 1993), have found little evidence to suggest that there are profound differences in ethicality between social workers, psychologists, and mental health counselors; however, it should be noted that the mental health practitioners surveyed in these studies were working in similar outpatient environments and were likely impacted by hierarchical group norms. With such discrepancies in overall training between the disciplines, it is essential that greater clarity be brought to the attention of a supervising psychologist, especially as it pertains to master's level therapists under their supervision when working in the less structured settings of wraparound (MST) in-home therapy.

When a master's level therapist commits an ethical breach of conduct, the licensed psychologist is at professional risk from the state licensing boards, as well as through possible litigation through the civil courts if incompetence can be proven and a cash settlement is pursued. The idea of competency can not be ignored in any discussion of supervision. Vasquez (1992) notes that "most traditional training fails to teach how to apply the basic principles of counseling beyond the ethos of the majority culture” (p. 198). This may become particularly limiting where in-home therapy is concerned, due to 
inherent variances and intensified in-vivo cultural and socioeconomic nuances. Add to this the findings that therapist are often reluctant to seek help in these sorts of difficulties (Deutsch, 1985), and the potential for ethical violations brought about by failure to seek consultation increases. With in-home therapists being expected to maintain a higher level of autonomy in regards to scheduling and session-norms (distribution of time per week, venue as to where therapy is to take place, etc.), it stands to reason that there may be increased reluctance to share particularly charged topics with supervisors. Cunningham and Henggeler (1999) note that supervisors can foster an atmosphere of support by recognizing the inherent challenges involved with MST and multiperson therapies, and that the therapist should be allowed to share in the problem-solving process that will allow them a change to develop as clinicians without fear of unjust labels of incompetence.

There may also be distortions occurring with those in-home therapists who are working in the field in that they may feel that an office-based psychologist supervisor may not be aware of the subtle differences between structured outpatient therapy and that of in-home MST (e.g., a “front-line” mentality). These potential attitudes may be best described as personal blind-spots that may negatively affect the overall care of clients (Vasquez, 1992) and blur the line between support and personal difficulties associated with boundary violations. Supervisees, in an effort to self-protect and maintain their occupational positions, may be unlikely to reveal some of the more ethically dangerous behaviors that they are participating in within the office or home environment. Many supervisees have also addressed the fact that their clinical supervisors have limited knowledge of the applications of defensive practice that are needed in working in any environment, but especially where in-home therapy is concerned (Plante, 1999). 
Henggeler et al. (1995) suggest that MST therapists may in fact have superior supervision due to increased caseload collaboration with colleagues and inclusive multidisciplinary meetings. Still, there are some glaring holes in the argument as treatment focus may aid in the disseminating of proper therapeutic treatment, ethical concerns and boundary violations may not be so readily addressed in this group format. Furthermore, other writers have indicated that specialized training and supervision may be needed in order to ensure the proper implementation of therapeutic interventions such as those found in wraparound multisystemic treatments (Schoenwald et al., 2003).

This argument is reinforced by Henggeler et al. (2002), who described complications with conducting research on supervision in real-world settings, indicating the concerns over therapist adherence to supervisory dictates as well as complications stemming from a lack of monitoring in the field. In regards to MST in-home therapy, the most disseminated supervision model is the Supervisor Adherence Measures (SAM) proposed by Henggeler and Schoenwald (1998). SAM is designed to maximize the efficiency of supervision between the support staff associated with multisystemic treatments in family therapy. It was designed by expert consensus and focuses on those features that are most pertinent to MST therapeutic delivery. The constructs delineated by SAM include: supervision structure and process, promotion of analytic family-focused process, maintaining treatment principles of MST, and increasing clinical competence of the actual therapist performing in-home work.

Of the 43 items suggested in the Supervisor Adherence Measure (SAM), only one item allowed for the broaching of ethical concerns that were outside of the MST model of service delivery: It was easy for team members to acknowledge frustrations, mistakes, and failures. The SAM model seems to be an effective model for supervising the 
techniques and general outcomes of each MST case, yet seems to discount the potential for ethical quandaries that may be occurring despite therapeutic progress.

\section{Specific Ethical Concerns in Multisystemic Models of Therapy}

Before one considers the environmental effects on therapy that in-home MST models present when compared to traditional outpatient models of treatment, a discussion of the inherent ethical complications of family therapy must be elaborated. Several authors have discussed the challenges of multiperson (Family) therapy modalities (Lakin, 1994; Fine \& Turner, 1991), and have found the process to be rife with ethical snares. Lakin stated, "Multiperson interactions generate characteristic behavioral patterns and an emotional ambiance that differs significantly from that of dyadic psychotherapy” (p. 344).

In reviewing the literature that focuses on dual relationships and non-sexual boundary violations, several key factors emerge that pertain directly to the implementation of wraparound, in-home therapeutic work: 1) Confidentiality, 2) Role Confusion, 3) Client Diffusion, and 4) Unintentional Witnessing. Each of these factors is worthy of ethical consideration, especially in regards to disparities found between officebound and in-home therapy. The term "role confusion" is substituted here for the more commonly used "dual role" concept, due to the differing and broader aspects of the relationship issues present in wraparound therapy. The topic areas of client diffusion and unintentional witnessing are posited to draw attention to critical areas of concern that are specific to the in-home therapist. 


\section{Confidentiality}

Issues of confidentiality are often the most frequently described professional dilemma faced by therapists (Pope and Vetter, 1992), and are the number one ethical breach by neophyte therapists in the field (Fly et al., 1997), even though confidentiality has been endorsed by many professionals as the "most ethical duty" (Crowe et al., 1985). Several studies have shown the complications found in the ethical practice of therapist in regards to confidentiality requirements. Baird and Rupert (1987) found that $50 \%$ of their sampled psychologists did not inform their clients of the limits of confidentiality during their initial session. Those that were made aware of such limitations were less likely to disclose child punishment and neglect behaviors and were also less likely to expand upon the use of illicit substances and the incidence of criminal activity (Nicolai and Scott, 1994; Taube and Elwork, 1990). There has been much written on confidentiality in the rural setting, and many of the same tenets hold true for the wraparound therapist who visits an urban household. Confidentiality may be compromised the moment the therapist strides to the front door of a client's home, while curious neighbors peek from behind their curtains. Stockman (1990) describes the problems with confidentiality breakdowns in the rural environment as creating devastating breaches "where close personal ties make the dissemination of information (or gossip) fast and thorough” (p. 40). Instead of the corner store however, the in-home therapist may be confronted by an active city street, single entry apartment building, or enclosed plaza. Regardless of the cause, with wraparound therapy, confidentiality is likely the exception rather than the rule. The literature is scant at best, and what little is out there primarily deals with client overlap in rural locales that have limited mental health services. Schank \& Skovholt 
(1997) stated, "therapy choices may be limited in rural and small communities, and there is invariably an intersection of clients with other clients” (p.48). In wraparound therapy, this intersection occurs within households, between family members, and sometimes even with non-related members that because of proximity, enter into the unstructured therapeutic sphere whenever the therapist enters the home.

To further complicate matters, the wraparound process is designed to reconnect the target family with outside resources such as neighbors, extended family, clergy, and even sports coaches. In this, the family is "empowered to assume responsibility for putting together its own support network” (Huffine, 2002, p. 810). From a strictly supportive framework this may be viable, but often times there are intrinsic factors involved that require traditional confidentiality consideration such as family secrets, drug dependency, sexual abuse trauma, interpersonal difficulties, and undiagnosed mental health needs in non-client family members. Relying too much on the community support framework may inadvertently expose the clinician to unenviable situations where information needs to be controlled, yet the sheer number of involved helpers makes the task nearly impossible. Damage to the family system can occur when the therapist is unable to direct the volatile information that is flowing freely through the support framework inherent in wraparound therapy. Is it truly necessary that a high school basketball coach sit in on a school meeting where the child-client's family history of bipolar disorder is revealed? Though the answer to this may be an obvious and resounding no, theory and existing APA and other professional guidelines may not be as ironclad and protective of confidentiality where wraparound therapy is concerned.

Inter-therapeutic confidentiality has been addressed in many ways, varying from no secrets allowed between members, to complete compartmentalization of information 
(Hare-Mustin, 1980; Margolin et al., 2005). When a child is the primary target of therapeutic intervention, whether in the outpatient office, or in the home environment, confidentiality issues become even more complicated. One must question the ability for an in-home therapist to address the potential issues of trauma experiences or fears that are directed at the parents of the client when one is sitting in the family living room. An inhome therapist may be a professional, but child clients know that the rule of the house places his or her parent's at the top of the information and power hierarchy. How then can secrets be shared, and are some secrets too dangerous to broach when not in the controlled environment of a professional office? Patten (1991) describes how the specifically controlled office environment can allow for a modified style that allows the framework for individual family members to express hidden secrets without fear of reprisal or the collapse of the original family system. When dealing with such "hidden secrets" the in-home therapist is not only unlikely to be able to maintain confidentiality, but also opens the door to ethical quandaries and even physical danger to himself as well as the individual family members who share these explosive secrets.

One other factor to consider in regards to confidentiality is the fact that the dissemination of critical case information is less contained in an in-home setting than it would otherwise be in the outpatient office. Plante (1999) noted that many mental health professionals can be "careless with patient information that is left on desks of shared offices, in cars, at home, in coffee shops and elsewhere” (p.402). What happens when the therapist's very office is the car and progress notes are sometimes written on steering wheels? In mental health agencies, confidential information such as that found in case files is often kept under lock and key in a limited-access office. Wraparound case files may be housed in the same office environment, but progress notes and incidental 
paperwork such as releases are sometimes less secure. It is not hard to see that this process likely has more potential for lapses in confidentiality simply due to the procedural differences involved.

\section{Role Confusion}

Many have alluded to the hazards of dual relationships within the therapeutic relationship. Koocher and Keith-Spiegel (1998) stated “.. . we are convinced that lax professional boundaries are often the precursor of exploitation, confusion, and loss of objectivity” (p. 172). Similar claims were made by Pope and Vasquez (1998), and Kitchener (1988). Lazarus (1994) disagreed, claiming that stepping outside of the rigid constraints proposed by the existing guidelines may allow for therapy to be enhanced.

According to Kitchener (1998) three factors identify potentially dangerous dual relationships. These include: 1) incompatibility of expectations between roles, 2) divergence of obligations of different roles, and 3) difference of power and prestige between the professional and the client. Lakin (1994) also addressed the power differential between therapist and client in regards to multiperson treatments that are the bread and butter of wraparound, in-home treatments. He warns of the "temptation to interpret character and symptoms in ideological terms” (p. 345). That is, differences in religion, race, culture, or political oppression may be inadvertently pathologized by the well-meaning therapist who is accustomed to specific expectations of a successful, intact family unit. Fine and Turner (1991) described this phenomenon as it applied to multiperson family therapy and how potentially restrictive the defined values and experiences of the therapist could be when observing such issues as marital fidelity, 
gender roles, pregnancy, and child discipline. Other examples might include work ethic, use of public welfare, and insistence on college education as lone means for selffulfillment.

Within the framework of in-home therapy, the divergence of obligations of different roles creates continuous complications that are not easily dispelled regardless of the amount of care a therapist may take in preventing them. Horst (1989) states that one of the major criteria "between a dual relationship and a non-harmful overlapping one is not outside contact per se, but rather the degree to which the outside relationship allows therapist and client to remain in appropriate roles” (p.22). One must consider the ramifications of a relationship literally defined by this very outside contact that so often poses difficulties for office-bound therapists. Can a genuine therapeutic relationship be forged within a client's living room? Are there unavoidable role confusions that result when a therapist's weekly session takes place at the kitchen table as the evening meal is prepared mere feet away? How should a therapist react when handed the family's new baby, or when an Irish setter demands attention with its squeaky toy? Pope \& Vetter (1992) described the demands of the "non-professional” atmosphere contained in a client's home and showed that it was an area of concern for psychologist in both the direct practice and supervisory roles.

Miller \& Maier (2002) described the differences between both non-sexual boundary crossings and non-sexual boundary violations. Though the distinction may be easily discerned at times, the scholars make a strong case for "slippery slope” activities that lead to more severe ethical quandaries. Examples of boundary crossings include the seemingly innocuous events as appointment changes, choices of where to meet for therapy, and therapist self-disclosure, while boundary violations are more easily 
identified as manipulating clients for personal gain and falsifying insurance claims forms (p. 310). Of course the problem with these neatly categorized infractions stem from the fact that in-home forms of therapy such as wraparound are at a serious disadvantage to control these defined boundary crossings. If an in-home therapist needs to change an appointment with a family member, it is likely that they will do so directly. There are different expectations involved in this process. An in-home therapist is more likely to engage in boundary crossings by stating that he or she is running late due to traffic, a protracted dentist appointment, or a prior client issue. Changes in therapy times will undoubtedly lead to self-revealing statements by the therapist as to why they are postponing the appointment that would generally be mediated by a secretary in the office environment. The boundary crossings described by Miller \& Maier are so commonplace in multisystemic therapy, they are virtually daily occurrences. This is of particular concern as therapists have been sued due to the primary complaint of self-disclosure affecting the boundaries of the therapy (Peterson, 2001). Likewise, Goldstein (1997) found that therapists who "self disclose for personal reasons either to maintain separateness from the client or gain empathy from the client, may take advantage of clients” (p. 46).

Martinez (2000) constructed another model for boundary crossing classifications by identifying several key areas of concern. Though the list includes clear references to straight fraud and sexual infractions, the most pertinent reference to crossing behaviors is identified in the author's third principle. Principle three includes self-disclosure, gifts, inappropriate therapist language or dress, and inappropriate social contact.

Some researchers identify the disgruntled agency employee who, through conscious or unconscious means, directs the client to act out against the helping agency 
to fulfill the therapist's own grudges and revenge fantasies (Miller and Maier, 2002, p.315). With wraparound services, this type of interplay can be directed at the therapist's employer, a psychiatrist who did not treat the psychologist with professional courtesy, or even a school district that has shown little regard for the therapist's proposed interventions.

To further complicate matters, wraparound therapists are often responsible for traditionally non-therapist duties that would rarely emerge within the controlled office environments of their outpatient therapist colleagues. In-home therapists may be in a position where they need to assist with resource facilitation or transportation by sheer necessity, though many agencies are creating agency guidelines for such cases to help limit liability. Prinze \& Miller (1996) identified these situational demands (lack of transportation, child care issues, resource scarcity, etc.) that create additional ethical quandaries for the in-home therapist delivering MST.

Also, the very nature of MST lends itself to cultural and political activism and the identification of the “. . . systemic racism and oppression on many families, and how these experiences can create obstacles to treatment engagement that must be addressed for contextually responsive treatment” (Stern, 1999, p. 283). MST has been largely disseminated to children and families that are Medicaid eligible and who are not primarily utilizing private forms of insurance, and who are likely to be from lower income strata (Henggeler et al., 1995). The APA code is vague and does not explicitly address the demands on community psychologists and therapists under their supervision as it relates to specific service needs of the poor, unemployed and disenfranchised (Pope and Garcia-Peltoniemi, 1991). Issues related to this dynamic may involve lying about mental health conditions in order to give clients additional mental health hours and 
extended resources, while also allowing for dependency issues to arise in terms of the therapist as "ultimate rescuer." With in-home therapy, the impetus is placed on not only aiding the target child and his family, but in bolstering and enhancing the mesosystems involved in the child's life. Often times this directive tends to gravitate away from traditional therapeutic practice and create the need for the wraparound therapist to be the defender of the family, where the needed role of advocate can easily be at odds with existing educational and managed care insurance systems.

This emersion into the family system that comes from potential role shifts associated with a variety of in-home situations (e.g., looking at a roll of vacation pictures, watching the family hang garland on their Christmas tree, the keeping of Pepsi in the house in case the therapist wants a drink, etc.), can make the client system more appealing than what might develop in the outpatient office setting. Bennett (1997) noted the danger in this, as therapists are more likely to form unethical relationships that are riddled with boundary violations with those clients that they find more appealing. Of additional concern is the research that states disadvantaged parents have reduced expectations of therapy when compared to more advantaged parents (Nock et al., 2001). The combination of a therapist who feels placed in a protective, elevated role mixed with a family system that may be less inclined to understand the general outcomes to be expected from therapy, sets up a dangerous situation where boundary violations can occur and where a less experienced, or power-driven therapist can overstep the bounds of the profession.

Wraparound therapy is directed at a child in the target family, but the family systems approach will always include parents and other important adults that affect the child's life. Though role confusion is possible with child clients, greater attention needs 
to be placed on the potential distortions occurring between the in-home therapist and the adults in the family system.

Epstein (1994) warned of self-disclosures by the therapist and indicated that repeated glimpses into the therapist's personal life created an exploitative situation in the therapeutic union. Likewise, Brodsky (1989) went so far as to suggest that therapists who frequently self-disclose personal information to their clients are far more likely to engage in sexual contact and other unethical boundary breaches. This is an important concept to consider when one compares outpatient and in-home therapies addressed through wraparound services (MST). Few would be surprised to learn that when one leaves the concrete parameters of the mental health office, a therapist becomes less defined in his or her psychological role and it may be easier to allow permeation of the professional boundaries during the therapeutic session. For the in-home therapist, this lack of physical boundaries offers a legion of inadvertent self-disclosures simply due to the context of the therapy. Car problems, sickness, child care issues, and personal holidays are rarely filtered through the neutral voice of a secretary as they often are with outpatient therapy; there is no buffer of information between the in-home therapist and the client. Usually the in-home therapist will directly call the family at their home, hurriedly describing any number of potential disruptions that may have delayed, cancelled, or rescheduled the meeting time. This unintended but natural aspect of wraparound allows clients to gain access into the therapist's life.

Goldstein (1997) also alluded to the dangerous content of personal revelation, noting that therapists who disclose for personal reasons in hopes of gaining sympathy or to maintain separateness may in fact be taking advantage of the client in question. Add to this that many authors identify the most fragile clients for this type of disclosure as being 
those that are readily inclined to adopt the characteristics of the therapist (Goldstein, 1994), or act impulsively due to poor boundary regulations (Epstein, 1994), and a case is built that shows the inherent dangers of unmonitored personal disclosures. This is especially true as the focus of MST and in-home therapy interventions are very often those that are disenfranchised, come from low SES backgrounds, and are often not confident in challenging the directives set-forth by the in-home therapist.

Again, this discussion is directed toward the adults present in the family system of a wraparound targeted child. With children and adolescents, self-disclosure is considered to be a more open process and in many ways does not afford the same kinds of risk. Papouchis (1990) described the importance of self-disclosure with children to teach life lessons and engage in universality to offer a broader framework for therapy and security.

\section{Client Diffusion}

Client Diffusion is potentially the least researched, as it applies to specific kinds of therapy such as family systems and is generally not applicable to a wider scope. While outpatient therapists have the natural boundaries of the waiting room, a secretary, and an office door, the in-home therapist has no such luxury and struggles to find physical demarcation between client and non-client. Outpatient therapy also includes traditional social nuances that invite particular members into the therapy process, such as verbal invitation by the therapist for a family session, or an extension to therapy time to review another family member in the event that they also need services. No such nuances exist in an in-home session. At any moment the therapeutic session may include any number of individuals from additional children to extended family members and even friends and 
neighbors. Though it is possible to limit the amount of intrusion during session, it is not always feasible to direct therapy in this manner.

At times the identified client that obtains services and brings the therapist into the home initially may not be the member that requires the most significant attention. Within the practice of multiperson structural and intergenerational family therapies, this kind of broad sweep addressing the entire constellation of issues contained in the family is not uncommon. When family dynamics are of central focus in the therapy, "it is rarely clear who is the real patient or client” (Lakin, 1994, p. 347). The APA code of ethics addresses this potential blurring between client and non-client, but the standard may gravitate toward the ideal rather than the pragmatic - especially where in-home therapy is concerned.

When the environment is less controlled, the ability to take these "reasonable steps” drops considerably. Again, the APA code of ethics is often the paragon used un directing the course of therapy for clients through community mental health agencies. Master's level therapists in social work and counseling must often apply these standards as if they were their own. The reason for this is twofold: for one, the APA ethics code is the "gold standard” to which other fields adapt their own standards, and secondly, as noted earlier, psychologists are often responsible for the supervision of these master's level therapists and it is that state license that is at risk if litigation were to occur due to ethical negligence.

Grosser and Paul described some of these ethical concerns as far back as 1964, while the topic of client diffusion within the family system has more recently been described as a danger to the therapist who wants to be all things to all people, and in their "hopes of maintaining and sustaining the concept of the utopian family, a therapist may 
tend to work toward unattainable and even unwanted goals within the family ...”

(Weiner \& Boss, 1985). Multisystemic treatments complicate this dynamic as the therapist is witnessing the family within their natural environment, for better or worse, and more often for worse. The desire to "correct" maladaptive behaviors in the system will lend itself to the in-home therapist extending a wider and wider scope in order to make more uniform and lasting changes. When performed correctly, the family’s overall mental health improves and communication between members is facilitated as per the conceptual models of Minuchin and Bronfenbrenner; when it fails, the in-home therapist is overwhelmed by an unlimited flow of potential clients and varied interests and issues, while the target child dissolves into the dysfunctional fabric of the systemic quilt.

\section{Unintentional Witnessing}

A common complaint of the in-home therapist that operates within an MST framework is the inability to control the flow of information obtained. When a therapist is within a client's home there is a tendency to become privy to unwanted, unsolicited information, which is often not relevant to therapeutic practice, but which alters the relationship between the client and therapist in subtle ways. Pope and Vetter (1992) addressed this issue in the broader context of confidentiality, but added that APA members struggled immensely with situations that involved child abuse reporting and some situations that involved potential risks to others.

Several studies have suggested that many therapists are more likely to ignore laws of mandatory reporting if they feel that it will interfere with the greater goals of therapy and functionality in the family system (Koocher and Keith-Spiegel, 1990; Pope and Bajt, 
1998). Not surprisingly, Delaronde et al. (2000) found that of the 382 social workers, pediatricians, teachers, and physician assistants that responded to a self-report questionnaire, only social workers showed a significant interest in creating an alternate form of mandated reporting that differed from the existing standards. Social workers more commonly work in the home environments than the other professions listed. This interest in creating an alternate system that is initially less punitive and more supportive would not only appeal to social workers, but also to those therapists that are engaged in in-home therapy. Another survey of interest (Kennel, 1997) showed that outpatient therapists were more likely to report sexual victimization to the authorities when the child was younger, due to the belief that the effects to personality development would be more profound. In Kennel's study, 31\% of respondents (out of 347) failed to report a past incident of child sexual abuse that should have been reported based on mandatory reporting guidelines. This is an alarming statistic, and one that should be strongly considered when extrapolating these findings to in-home therapy where the offenses may be more blatant and may create a perfect environment for lawsuits and loss of licensure to the supervisor that turns a blind eye to such reports of misconduct.

It is important to identify the potential risks the in-home therapist must subject themselves to in relation to unintentional witnessing of criminal and illegal activity that office-bound therapists rarely, if ever, encounter. Examples of these situations include, but are not limited to: active drug use and/or sales by family members from the home (including prescribed medications); animal (pet) cruelty or neglect; unseemly sexual relationships between non-client family members including statutory rape situations; and possessing and distributing stolen/illegal goods. Of specific interest in this category are abuses within the welfare and medical system where a therapist may be aware that a 
client is selling food stamps for liquor or cigarettes or even babysitting fees. It is not uncommon to find clients that misrepresent their mental health symptoms in order to gain additional social security support. As was described by Taube \& Elwork (1990), in the outpatient setting, where the limits of confidentiality are described, there are fewer disclosures made in reference to potentially reportable offenses, especially as it applies to child abuse and neglect. This filtering is far less likely to be maintained in regards to the in-home setting where disclosures may still not be given, but where actual witnessing may occur.

Child abuse and neglect are often confronted in the wraparound environment. Through vigorous literature review, Schumacher et al. (2001) suggest that parental behavioral and psychological characteristics may have the largest relation to neglect, and that limited socioeconomic resources are the most consistently documented risk factor for neglect (p.231). This description is well matched to the general clientele of multisystemic treatments, who as a general rule require more intensive services due to elevated economic and interpersonal needs. The therapist must decide if a home environment is sufficient enough to meet the needs of the child client. Outpatient therapists may not be faced with the concrete observations of rotted floorboards, insufficient food stocks, unpaid gas bills, and insect infestation that can affect the inhome therapist. Therapists that have worked in the home environment often cite problems with current child abuse reporting laws as they relate to the ability to maintain a therapeutic relationship with a child and that client's family. Add to this the fact that research has shown that decisions about child abuse reporting have been linked to a therapist's certainty that such abuse is taking place, and in-home therapy appears to be more susceptible to potential reporting violations and supervisory needs in this regard 
(Nicolai and Scott, 1994). What is frightening is that the same research has shown that approximately $40 \%$ of the respondents (in a sample of 204 therapists) stated that they "would be unlikely to report child abuse depicted in a case vignette, even though nearly all of the self-declared non-reporters were certain that abuse was occurring” (p.158).

Emery and Laumann-Billings (1998) questioned the feasibility of mandated reporting within abusive family relationships where therapeutic intervention was involved. The authors posit a frequently asked, yet considerably emotionally charged and legally catastrophic issue - that of exemptions in reporting rules when a family is actively involved in therapeutic treatment. This topic is an especially complicated challenge for in-home forms of therapy. Ideas to create flexible reporting standards have been identified by Finkelhor and Zellman (1991) take only traditional outpatient therapy into account, and although there has been essentially no movement in slackening the mandatory reporting standards for mental health professionals that work with children, it is self-evident that the burden of these expansive laws create greater ethical dilemmas for the in-home, wraparound therapist where neglect and abuse charges may be far more visible and demand more critical attention. Where an outpatient therapist may turn a blind eye or choose not to record issues related to unintentional witnessing, with no one being the wiser, those therapists that work in the client's environment may find that they are faced with the disturbing task of confronting abuse or neglect that occurred in their very presence. Furthermore, litigation has occurred in recent years which challenged the assumption that mental health professionals are fully protected when making appropriate reports on child abuse to child protective services (Caudill and Pope, 1995). Several cases in California have seen well-intentioned psychologists sued for making such reports in keeping with mandatory reporting laws. 
The purpose of this research was to compare outpatient with in-home forms of therapy to develop a greater understanding of the experiences that each face in regards to ethical quandaries and violations. The areas of focus were predominantly associated with the boundary violation literature that was described above. Using the four categories of confidentiality, role confusion, client diffusion, and unintentional witnessing, this research attempted to address gaps in supervision and potential ethical quagmires that supervising psychologists need to navigate if they work with agencies that supply MST to the community.

Epstein and Simon's (1990) Exploitation Index was used as a theoretical model for the ethical questions to be asked in this survey. Modifications were made to this specific survey to better include the experiences of wraparound (in-home) therapists as well as broaden the context to include environmental factors that may lend themselves to greater risk for ethical violations (regardless of the therapist's actions). While the Exploitation Index primarily focuses on confidentiality and role confusion issues associated with outpatient therapists, it does provide a structured format in which additional questions pertaining to client diffusion and unintentional witnessing could be added. 


\section{Statement of the Problem}

It is estimated that $40 \%$ of the ethical complaints brought before the APA each year are related to boundary violations between client and therapist (Staal \& King, 2000). Woody (1998) noted that complications in defining a precise number of ethical complaints levied against psychologists as many are settled outside of the court systems and never come to the attention of state licensing boards. Boundary violations are a wide-spanning descriptor that may include everything from confidentiality breaches and therapist self-disclosures, to more pernicious activities such as overt manipulation and even sexual contact. Above all, multiple relationships and dual roles warrant intense scrutiny as they have often been earmarked as the most frequently encountered ethical dilemma in the United States (Pope \& Vetter, 1992).

Of particular interest is the fact that many outpatient offices and both profit and non-profit community agencies employ psychologists in multiple occupational roles of therapeutic overseer and direct supervisor of master's level therapists with counseling and social work backgrounds. When the supervisees perform unethical professional behaviors, the supervisor may often become embroiled in the legal fallout that sometimes ensues. With lawsuits increasing against licensed psychologists, and with state licensing boards being notoriously critical of lapses in supervision judgment, it is all the more important for psychologists who engage in supervision to be aware of the dangerous quagmires that exist not only in the office environment, but in the emerging in-home therapy realm of multisystemic treatments as well. The APA code of ethics is often the paragon used in directing the course of therapy for clients through community mental health agencies. Master's level therapists in social work and counseling must often apply 
these standards as if they were their own. Many of the ethical codes devised by social workers and counseling professionals follow a similar vein of thinking that is concurrent with the overall principles of the evolving APA code. Some authors have even suggested that specific ethics courses should be mandatory for those students that are assuming careers in the helping professions, and that a unification of universally accepted norms between professions is essential to maximize treatment effectiveness and prevent disastrous results (Gawthrop \& Uhelmann, 1992).

Multisystemic treatments (also described as MST, wraparound services, and inhome therapy), has been described as the "building of constructive relationships and support networks among youth with emotional and behavioral disorders” (Eber et al., 2002, p.171), to a definitional “Tower of Babel” that is yet to find its true design (Malysiak, 1998). It is an approach that has evolved in an attempt to coalesce the often chaotic distribution of services that are directed at target children and their families. Wraparound's origins stem from a grass-roots movement in intervention techniques that arose from the general frustration experienced by families, schools, and mental health providers over what was often considered fragmented, rigid services for children with serious mental health considerations (Burchard et al., 1993). Though resource coordination is often at the heart of the wraparound process, the emergence of the inhome, or mobile therapist, has become a growing occupational outlet for many master's level counselors of divergent educational backgrounds. Yet despite this emergence in therapeutic delivery, there has been little empirical work on the importance of the family microsystem in the treatment of oppositional youth as it applies to MST (Stern, 1998). It should be noted that MST is simply a method of service delivery, rather than a specific theoretical therapeutic intervention on to itself. In addition, the focus of MST is directed 
at children and their families, and so it is that this survey was specifically applied to those professionals that work with younger clients.

\section{Purpose of the Study}

Mobile therapists stem from educational, social work, and counseling backgrounds and are most often master's level professionals. Farmer et al. (2004) stated that “MST is delivered via MST therapists (usually master’s-level professionals) who work intensively with a few families for a time-limited duration” ( p. 864). Some are licensed by the state in which they practice (such as licensed social workers and licensed counseling practitioners), while others are not. Managed care has dramatically impacted the ways in which mental health services are distributed, "psychotherapists are increasingly practicing in multidisciplinary groups rather than traditional, independent, ‘solo’ settings” (Pomerantz et al., 1998, p. 35). These multidisciplinary groups have dramatically affected the ways in which therapy is performed, the time and settings where it occurs, and the style and modalities which are employed to do treatment. With all of these changes, supervision and ethical guidelines of treatment become even more essential to the operation of proper standards of care.

Unlike traditional forms of outpatient therapy that address the needs of its clientele in office and hospital settings, the MST model of therapy is performed in the living rooms and kitchens of the people it seeks to aid. Within this unregulated environment, therapists must be able to identify potential ethical dilemmas as they arise. Current research on this topic is still relatively in its infancy and one must examine the ethical cues from a variety of existing sources for guidance. 
Several surveys have been utilized to attempt and identify trends in thinking and the incidence of non-ethical behaviors in the workplace with psychologists and master's level therapists. Two in particular were of interest to this study, as they addressed areas of concern found in boundary violations that occur in therapy (Pope et al., 1987; Epstein \& Simon, 1992). Although surveying psychologists, the Pope survey offers a wide theoretical framework in which to examine the continued ethical dilemmas from all therapeutic disciplines (psychology, social work, counseling, and, even, psychiatry). Epstein \& Simon offer further survey items that are of use in identifying boundary violations, especially as they apply to role confusions and misuses of the inherent power differentials contained within the therapeutic relationship.

Another goal of this research was to identify possible lapses in supervision of therapists that operate under the MST model, in hopes of protecting psychologists in the field who are responsible for these master's level professionals regardless of the setting in which therapy is conducted. Lapses in direct supervision, as well as the overall monitoring structure elicited by the outpatient office and accompanying personnel, may create a potential for increased ethical violations. It is estimated that in-home therapists, because of the nature of the position, are not as closely monitored by supervisory level professionals, and that they are less likely to engage in informal supports that are the benchmark of self-reflected therapy. Coster and Schwebel (1997) described some of these essential criteria that maintain a healthy therapist and reduce ethical violations. Two of their ten criteria were formal and informal supervision. Even when formal supervision is mandatory, those involved in MST may offer skewed perspectives concerning their practice, and their lack of contact with fellow therapists over the course of the work day only intensifies the potential for professional misjudgment. 


\section{Research Questions}

If it is true that the differences between in-home (MST) therapists and officebased, outpatient therapists impact the delivery of these services, we should expect to see different types of responses to the ethical situations present in these varied settings. This research specifically examines differences in application between these two styles of therapists in both style and setting, which may in turn impact ethical decision-making as it relates to the four categories of confidentiality, role confusion, client diffusion, and unintentional witnessing. Therefore, the following research questions were tested:

1. Will therapists (both in-home and office-based) who have had a specific course on ethics in their masters or doctoral training report significantly different ethical concerns for people in their position compared with therapists that did not have such a course? The variables are ethics course matriculation (IV) and the four ethical dimensions of Confidentiality (questions: 3, 6, 23, 28), Role Confusion (questions: 1, 8, 9, 12, 13, 15, 16, 18, 26), Client Diffusion (questions: 2, 10, 17, 27) and Unintentional Witnessing (questions: 5, 7, 11, 19, 20, 29, 30) (DV).

2. Will therapists (both in-home and office-based) who are state licensed report significantly different ethical concerns for people in their position than those therapists who are not state licensed? The variables are ethics course (IV) and the four ethical dimensions of Confidentiality (questions: 3, 6, 23, 28), Role

Confusion (questions: 1, 8, 9, 12, 13, 15, 16, 18, 26), Client Diffusion (questions: 2, 10, 17, 27) and Unintentional Witnessing (questions: 5, 7, 11, 19, 20, 29, 30) (DV). 
3. Will in-home therapists report participating in a significantly different amount of structured monthly supervision than their office-based counterparts? In addition, will in-home (MST) therapists report significantly different instances of asking for assistance in ethical inquiries from their acting clinical supervisors than officebased, outpatient therapists? The variables are type of therapist (IV) and the questions covered in Section III of the survey as they relate to supervision issues (DV).

4. Will different ranges of years of experience as a therapist in either setting (inhome vs. office based) show significantly different uses of supervision by a trained colleague? Specified ranges (i.e., less than 1 year, 1 year to 2 years, 2 years to 5 years, more than 5 years, but less than 10 years, more than 10 years but less than 20 years, and 20 years or more) will be considered through the use of an ANOVA.

5. Finally, will in-home (MST) therapists describe significantly different perceived ethical concerns for others in their position in relation to the four spectrums of Confidentiality (questions: 3, 6, 23, 28), Role Confusion (questions: 1, 8, 9, 12, 13, 15, 16, 18, 26), Client Diffusion (questions: 2, 10, 17, 27) and Unintentional Witnessing (questions: 5, 7, 11, 19, 20, 29, 30) (DV) when compared to their office-based, outpatient counterparts? In-home and office-based therapists will be compared on a number of individual characteristics (i.e., state licensure, age, gender, years of experience, race, education, theoretical orientation, years at position, and whether or not an ethics course was taken) (IV) to determine which 
differences exist. These differences will be statistically controlled in analysis of this research question.

In order to test these research questions, a survey instrument that both identified potential areas of ethical concerns, as well as therapist demographics and supervisory experiences was needed. What follows is a discussion of the methodology that tested the above questions. 


\section{CHAPTER TWO METHODOLOGY}

This chapter provides a discussion of the participants in the study, the process in how this sample population will be obtained, and the structure and design of the survey instrument to be utilized. In addition, this chapter will give operational definitions and elaborate on the analysis plan to be employed after the data has been collected.

\section{Participants}

In order to test the research questions, a sample of in-home and outpatient therapists was drawn. This study surveyed therapists from a variety of backgrounds about their experiences in differing therapeutic environments. Because the focus of this study was on only in-home and out-patient therapists, it is not efficient to perform a probability sample using existing lists of all therapists who held license in a particular locale (e.g., National Association of Social Workers or State Licensed Professional Counselors). Instead this study took a more focused approach, focusing on those agencies that utilize in-home and/or outpatient forms of treatment. It seems logical to direct the survey toward agencies engaged in in-home and out-patient work. For convenience, this survey specifically identified agencies in Western and Central Pennsylvania and Eastern Ohio who provided such services. Therefore, a contact person can be utilized to help assist in directing attention to potential subjects (i.e., current inhome and outpatient therapists), and a higher completion rate could be obtained as compared to random probability sampling. Viable agencies were determined by a combination of inquiry phone calls and through the use of available community resource 
compilations that list such services. The largest distribution of surveys were handed out at a monthly quality assurance meeting that meets in Pittsburgh each month and reviews wraparound and in-home therapy agencies in Allegheny County. More than 30 agencies were on hand at this May 2006 meeting, and 280 packets were passed out at that time. Additional agencies were contacted through the use of internet and phone inquiries to gain a broader range of data.

This study, because it focused on environmental aspects that are particular to specific kinds of therapeutic services (in-home vs. office based), was better served by a targeted sampling strategy that identifies those agencies that utilize MST wraparound therapy either primarily or as a component of overall therapeutic offerings. So, while this study proposed to use non-probability sampling (specifically, purposive sampling), it is most appropriate given the overall research questions and aims of the research. Babbie (1990) described the utility of purposive sampling stating, "In some instances, you might want to study a small subject of a larger population in which many members of the subset are easily identified, but the enumeration of all is nearly impossible” (p.97). In this particular study, the larger population of master's trained therapists of differing educational backgrounds (i.e., social work, counseling, psychology), are not the primary area of focus; instead, this study is comparing the smaller subset of these therapists who are employed through specific agencies that offer outpatient and/or in-home therapeutic services in order to identify differences in observed ethical dilemmas that may emerge from each. Add to this that wraparound therapy most often extends from those agencies that have already developed a comprehensive child and adolescent outpatient service, and one can see the benefits to utilizing purposive sampling in this regard. Furthermore, the 
use of nonprobability sampling (like purposive sampling) has been found to be appropriate when conducting exploratory research (Fowler, 2002).

Each of these agencies was contacted by a letter on West Virginia University letterhead followed by an initial phone contact with the director of outpatient services and the director of MST services. These person(s) were informed of my desire to administer the survey to their employees and a request for permission and support. Once permission was obtained, a follow-up letter was sent thanking the director for their cooperation and providing instructions on distributing the surveys. Specifically, the director was asked to place an enclosed packet into each employee's mailbox who works in either in-home or out-patient therapy within their agency. Included within each packet was an introductory letter describing the study and asking for subject cooperation, an informed consent sheet outlining the human subjects protections, a copy of the survey, and a self-address stamped envelope for return of the survey (See Appendix A).

The goal was to obtain a sample of 100 combined in-home and office-based therapists, with smaller groupings representing each of the styles. Given that this survey utilized a mail survey, it was prudent to invite a minimum of 350 practicing therapists within the designated area being targeted, as mail surveys often have low response rates (Groves et al., 1992). Given this, a number of steps were taken in order to improve the likelihood that the surveys would be returned (discussed below). Mail administration was chosen due to the potentially sensitive nature of this survey. Therapists are being asked to account for potential ethically-charged situations that they have encountered in practice. Because of this, it was imperative that they be allowed to complete the survey in a location of their choosing away from their workplace. The idea behind this is that it would both increase the response rate and also the veracity of the responses provided. 
As many of these survey items alluded to sensitive ethical issues that may place some therapists on-guard, techniques espoused by Lee (1993) were used to decrease response distortions common to these sorts of surveys. As Barnett (1998) noted, "asking sensitive questions is generally seen as problematic in survey research in that responses are considered as being particularly prone to error and bias” (p. 63). Researchers have addressed this phenomenon created from highly sensitive items that increases underreporting of behaviors and which skew validity of individual survey questions (Bradburn, et al., 1989). It is prudent to note that the definition of "sensitive items" used in this study is as follows: 1) that there is a potential negative "cost" involved if a respondent's superiors discovered the results, and 2) if anonymity makes any kind of difference to response rates, than the material in question is sensitive in nature (Crino, et al., 1985). The condition of anonymity was critical in order to both improve the responder rate of this mail survey, as well as reduce the response error-rate associated with particularly sensitive survey items (Barnett, 1998). An assurance of anonymity helps maintain the credibility of the research in question, and is essential when surveying ethical standards that are defined by a professional organization such as the American Psychology Association (APA) or the National Association of Social Workers (NASW). This is particularly important when using a self-report scale as those that report uneasiness about specific topics are likely to select themselves out of the entire battery of survey items (Bradburn et al., 1989). It was hoped that by using some of these methods listed that respondents would believe in their anonymity and also complete the entire survey with few omissions. One way in alleviating this concern for confidentiality was described by Nicolai \& Scott (1994) who used separately returned completed surveys and response tracking cards to both preserve the conditions needed for anonymity as well as 
the need to maintain a tracking form as to who had not yet mailed their surveys so that a follow-up letter could be sent to increase overall return rates. It should be remembered that low response rates have been responsible for the poor image of mail surveys with some social researchers and improved techniques are essential for valid research results (Dillman, 1991). In addition, IRB approval was sought in regards to this study prior to the mailing of the survey instruments.

\section{Operational Definitions}

For purposes of this study an in-home therapist is a master's degree or higher educated person who performs the functions of psychotherapy, regardless of theoretical orientation, within the home setting of the target client. Only those professionals with master's degree education will be invited to participate in this study.

An outpatient therapist is a master's degree or higher educated person who performs the functions of psychotherapy, regardless of theoretical orientation, within an office setting in an agency, school, or some other space that is not the living quarters of the client or his or her family.

The four spectrums of ethical dilemma that are the focus of this study are defined as follows:

Confidentiality is the expectation between the therapist and client (or client family) that the information shared during the therapeutic session will not be shared with non-supervisory personnel, and that the therapist will maintain strict control over access to documents, progress notes, release forms, and other critical information that could reveal details of the case. 
Role Confusion is any behavior by the therapist, whether consciously manipulative or unintentionally misdirected, where the traditionally understood roles of a competent therapist are altered, creating misunderstandings in the professional position with the client.

Client Diffusion is any occurrence during the structured therapeutic session where a non-identified client (or clients) issues or problems are discussed despite the fact that these topics have no direct effect on the positive treatment of the identified client.

Unintentional Witnessing in this study is any event directly observed or described to the therapist during the structured therapeutic session that is considered illegal such as drug use, underage smoking, sale of prescribed psychotropic medications, child neglect or abuse, and animal cruelty.

Supervision in this study is any structured time period where one clinician aids in the development of another, often less experienced clinician, in hopes of improving or advancing said therapist's clinical skills, case conceptualization, or ethical decisionmaking. This may be done in a group format or individually.

\section{Survey Instrument: General Discussion}

Self-reports have been criticized due to the tendency toward systemic bias that results from both the over-reporting of socially desirable behaviors (e.g. volunteer work), and the under-reporting of socially undesirable behaviors (e.g., drug use, sexually deviant behaviors, etc.) (Bradburn, et al., 1989). A further concern of scaled responses is their tendency to elicit a restricted range of potential responses dependent on the questions being asked (Feather, 1973). Likewise, positive correlations between scaled questions may lead to what has been identified as group response, or specific response tendencies 
that may show the respondent in a more moderate, less polarizing light (Alwin \& Krosnick, 1989). In an effort to curtail this effect, this survey utilized a scaled response category set that directs the respondent to identify their assumptions regarding the regularity that ethical issues arise in their specific setting (in-home vs. outpatient) for their colleagues. This format allows for the respondent to distinguish themselves from the actor in the question, while also identifying frequencies of behavior as opposed to judgments on this behavior.

Lee (1993) addressed the efficacy of these techniques that have been developed through careful instrument design. Lee identified the effectiveness of prefacing a sensitive question with a qualifier statement that reflects that the behavior or event has already occurred, as well as focusing on specific frequencies in the scale range of behaviors (e.g. once a week, once a month, once a year, etc.). Lee also suggested the utilization of the normative technique with regards to sensitive survey items, which allows respondents the opportunity to answer questions about friends and colleagues rather than themselves; the thought behind this being that the respondent will project their attitudes and behaviors into this unnamed friend or colleague and give an accurate representation of their own norms in reference to sensitive items. Dillman (1991) noted the low cost of and ease of implementation of mail surveys and noted their growing and continued majority use in social science research.

\section{Survey Instrument: Specific Items}

The survey questionnaire is divided into three sections. The first section presents a series of demographic questions pertaining to personal descriptive data such as race, gender, education, theoretical orientation, etc. The second section consists of 30 survey 
questions pertaining to the four defined spectrums as described earlier (confidentiality, role confusion, client diffusion, and unintentional witnessing). This portion of the survey has a mixed question format, with the varying categories being dispersed throughout in no particular sequence. In the final section, thirteen questions were designed to assess the level and type of supervision being offered to the respondent. The collection of these responses will be collected into a supervision sum score for use in the OLS analysis model.

Survey items were created through the use and modification of several instrumental studies (Pomerantz, et al., 1998; Epstein \& Simon, 1990; and Borys \& Pope, 1989), and additional items were added to account for the additional dimensions of client diffusion and unintentionally witnessing that were lacking in those survey items. The survey items adapted for this study were predominantly focused on ethical boundary violations in keeping with the literature. These boundary violations tended to gravitate toward two main dimensions, that of confidentiality breaches, or role confusion. Several other changes were made to both merge the varying survey items into one survey utilized here, as well as address deficiencies in the questions asked in regards to in-home therapy. The modifications made fall into three primary categories: 1) changes in word choice; 2) added examples; and 3) removal of sex-directed items.

Prior to the dissemination of this survey to the participants, it was given to six expert professionals that were already working in the field of MST and outpatient therapy. These expert professionals were asked to evaluate the instrument for the overall content validity of the questions, as well as offer insight into questions that may elicit defensive reactions in respondents. These expert professionals were instructed to take the survey as if they were a subject of the study, and were then asked to offer their 
viewpoints as to the individual question items as well as the survey as a whole. In addition, these expert professionals were asked to examine diction, grammar, clarity, and sequencing of the survey items.

Examples of questions that measure for confidentiality include:

- Completing paperwork of a sensitive clinical nature in a public location (e.g., coffee house, restaurant, classroom, etc.)

- Breaking confidentiality if the client is using drugs and/or alcohol and is under the age of 18 (e.g., reporting to parent, caretaker, pastor, probation officer, etc.)

\section{Examples of questions that measure for role confusion include:}

- Accepting an invitation to a client's special event (e.g., birthday party, baseball game, dance recital, etc.)

- Believing that the client or their immediate family member would be immeasurably helped if you were a permanent part of their life (e.g., extended mentor to the child, romantically involved with a parent, etc.)

\section{Examples of questions that measure for client diffusion include:}

- Having difficulties in maintaining the therapeutic environment due to intrusions by others that are not directly involved in the therapy, but who monopolize time

- Providing individual therapy to a relative, friend, or significant other of an ongoing client or their immediate family

Examples of questions that measure for unintentional witnessing include:

- Becoming privy to direct evidence that a client or underage member of the client's family is engaged in a sexual relationship with an adult that is more than three years their senior (e.g., a 16 year-old engaging in sexual contact with a 19 year old).

- Becoming privy to direct evidence that a client or their immediate family members are being cruel to animals or using animals in an otherwise illegal manner (e.g., dog fights).

For a full list of all of the survey items, please refer to the Appendix A 


\section{Analysis Plan}

Completed surveys sent back to the researcher were assigned a consecutive "study id” number. An SPSS database was created in order to enter the data. Data entry was completed on a rolling basis as individual surveys are received.

Prior research in this area has predominantly used separate ANOVAs to compare differences between professional groups (Pomerantz et. al, 1990 and Borys \& Pope, 1989). The Borys and Pope study examined the difference between types of therapists (i.e., psychiatrists, psychologists, and social workers) and different dimensions of unethical behavior in therapeutic relationships. While this approach is fine for assessing bivariate relationships, it is limited in that it does not allow the researcher to simultaneously assess the effects of other variables (e.g., level of education, years of experience, gender) on the dependent variable. The current research intends to overcome this limitation by using multivariate analyses to examine the effect of primary variable of interest (i.e., type of therapist) on reporting of unethical behavior by others in a similar position while also controlling for other important variables.

For research questions 1 through 3, difference of means tests compared the mean scores of in-home (MST) therapists with office-based outpatient therapists in regards to level of education, years of experience, supervision frequency, and accessibility to supervision. Due to the nature of question \#4 [i.e., "Will the more years of experience one has in a specific setting (in-home vs. office-based) show significantly different uses of weekly supervision by a trained colleague?], ANOVA was used to determine if there are indeed differences in this arena of inquiry. 
In order to test research question \#5 [i.e., "Will in-home (MST) therapists report higher frequencies of potential ethical concerns for others in their position related to the four spectrums of confidentiality, role confusion, client diffusion, and unintentional witnessing as compared to their office-based, outpatient counterparts?], four separate analyses were run. Each dependent variable (i.e., confidentiality, role confusion, client diffusion, and unintentional witnessing) is scaled based upon individual responses to specific questions on the survey instrument. All of the items in Part II of the survey assess the four spectrums of ethics examined in this study. Each individual item in Part II uses a response set that ranges from "never" to "weekly".

For analytic purposes a "never” response was scored a 0, “once a year” a 1, "several times a year" a 2, "monthly" a 3, and "weekly” a 4. Multiple items were used to assess each of the four domains of ethics. Thus to create each dependent variable, the scores to related items were added together to create a composite score for each subject. Referring to the items in Part II of the survey, the confidentiality composite score was created by adding the individual scores of items 3, 6, 7, 14, 20, 23, and 28 together. Likewise, the role confusion composite measure was created by adding items 1, 4, 8, 9, $12,13,15,16,18,22$, and 26 together. Client diffusion was created by adding 2, 10, 17, 21, and 27 together. Finally, unintentional witnessing requires items 5, 11, 19, 24, 25, 29, and 30 to be added together.

Prior to running the multivariate analyses (discussed below), a Cronbach's alpha was computed for each of the composite measures. A Cronbach’s alpha provides an assessment of the internal consistency of each composite measure (DeVellis, 2003). This allows the researcher to determine if all of the items that make up the composite measure are in fact all measuring the same thing (e.g., confidentiality). If the Cronbach's alpha 
suggested that the individual items do comprise a scale (i.e., an alpha score of .70 or better), than that composite measure was used as a dependent variable in the multivariate analysis. If the alpha suggested that the items do not comprise a scale, then each individual item would be treated as a separate dependent variable.

In addition, a factor analysis was performed on the items of the survey to determine their combined validity. The purposes of factor analysis described by Devellis (2003, pp. 103 - 104) include: 1) ascertaining how many underlying latent variables are being tapped by a group of survey items, 2) reducing the number of survey items into a single scale for analytic purposes, and 3) determining precisely which survey items are loading onto which latent variables. Specifically related to this study, it was imperative to 1) determine if each of the four ethics scales (i.e., confidentiality, dual role, client diffusion, and unintentional witnessing) being developed were in fact unidemensional, 2) use of the scaled items as dependent variables in the analysis (assuming they are unidimensional), and 3) identified which items were loading on the same latent variable in the case that the scales were not unidimensional.

The composite measures discussed above are interval level measures making ordinary least squares (OLS) regression appropriate for use in analysis. OLS regression was appropriate for this study because it allows for an investigation of the effect of several independent variables simultaneously on the dependent variable (Berry\& Feldman, 1985). In order to test research question \#5, the following OLS model was analyzed:

EXAMPLE: Type of therapist + level of education + supervision combined score + years of experience $=$ confidentiality scale . 


$$
Y_{j}=a+B_{1} X_{i j}+B_{2} X_{2 j}+B_{k} X_{k j}+E_{j}
$$

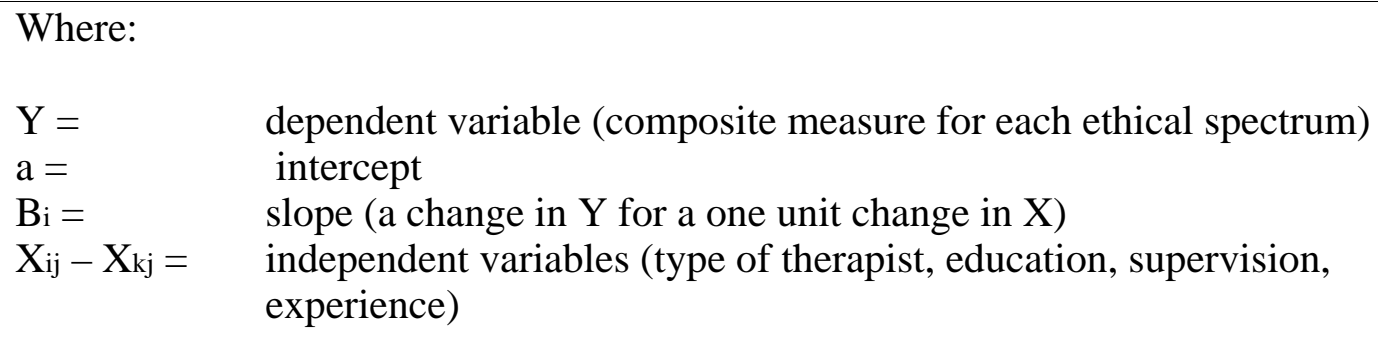

This type of study benefits from a multivariate analysis like OLS. With OLS the effect of each independent variable on the dependent variable can be examined while holding all other independent variables constant (Berry \& Feldman, 1985). In order to assess research question \#5, various OLS statistics were examined. First, the researcher determined if the overall model was statistically significant by reviewing the F-statistic generated by SPSS. Second, the R-squared was assessed to determine the amount of variance explained by the independent variables collectively. Third, for each independent variable, an unstandardized regression coefficient $(\mathrm{Bi})$ was computed that states the change in the dependent variable for a one unit change in the independent variable. The researcher determined which of the independent variables exerted a statistically significant effect on the dependent variable by looking at the t-tests. Finally, the researcher determined which independent variable exerted the greatest effect on the dependent variable by examining the standardized regression coefficients (i.e., beta weights). 


\section{CHAPTER THREE \\ RESULTS}

This chapter provides a discussion of the findings of the study and elaborates on the process by which data was collected as well as the statistical analysis performed in order to consider the overall implications to the field. Additionally, attention is directed toward the final construction of the four ethical scales used in this research.

\section{Findings}

Before going into detail about the findings, a discussion of the sample is in order. A total of 480 surveys were sent out to agencies serving adolescent clients both in-home and in-office in Pennsylvania and Ohio. Of these, 97 were returned producing a response rate of $20.2 \%$. While this rate is low, it is not atypical of a mail survey and could be lower given the sensitive nature of the topic relating to ethical perceptions of peers in the workplace. Some therapists may have felt uncomfortable filling out the survey fearing repercussions. Regardless, this is acceptable as the present research was meant to be a preliminary exploration of the ethical quandaries faced by in-home versus office-based therapists.

The characteristics of the sample are displayed in Table 1. The sample as a whole was relatively young with $61.9 \%$ of the respondents reporting being between the ages of 21 and $35(n=60)$, predominantly female $(n=76,78.4 \%)$, and overwhelmingly Caucasian $(\mathrm{n}=89,91.8 \%)$. Most of the respondents reported having a Master's degree as their highest level of education ( $n=88,90.7 \%)$ with the degree being granted in social 
work $(n=21,21.6 \%)$ and counseling $(n=25,25.8 \%)$ reported most often. Almost $60 \%$ of the respondents $(n=57)$ reported having worked as a therapist for less than five years and $45.4 \%$ of the respondents $(n=44)$ reported working at their current place of employment for less than two years. Additionally, when asked about their primary theoretical orientation, over $40 \%$ of respondents $(n=41)$ selected Cognitive Behavioral Therapy. Finally, 59.8\% $(\mathrm{n}=58)$ of the respondents reported primarily working with clients in the home, 38.1\% $(n=37)$ reported working in the office, and two respondents reported being split equally between the two. Refer to Table 1 for more demographic information.

\section{Factor Analysis}

In order to test the hypotheses, it was necessary to determine whether the four ethical domains (unintentional witnessing, role confusion, diffusion of treatment, and confidentiality) were actually operating as scales. In order to determine this, both reliability analysis (i.e., Cronbach’s Alpha) and factor analysis were performed. The items for each of the scales used the same response set [i.e., (0) Never, (1) Once a year, (2) Several times a year, (3) Monthly, (4) Weekly].

The “confidentiality” scale was originally comprised of seven items (please refer to Table 2). After initial analysis, a decision was made to remove three items from the scale (items 7, 14, and 20) as each of those items had a mandatory reporting aspect that seemed more confounding. The final four items performed well as a scale. The reliability statistic was in an acceptable range (Cronbach’s alpha = .7258). In addition, the factor analysis with varimax rotation extracted only one factor with the individual factor loadings being between .647 and .814. Thus, the four items were added together to 
create the "confidentiality scale”. The scores for the scale ranged from zero to sixteen. Higher scores on this scale indicate respondent's reporting a higher frequency of confidentiality violations by their peers. The skewness and kurtosis statistics indicate that the scale is close to being normally distributed and does not require any transformations.

The "role confusion” scale was initially comprised of eleven survey questions (please refer to Table 3). Two of the questions (items 4 \& 22) were dropped after preliminary analysis showed that those questions did not seem to show a role confusion, as much as modifying current practices by bartering for payment of services and altering diagnoses to prolong treatment. These items seemed more applicable under the role of a therapist, even though the practices are ethically suspect. The Cronbach's Alpha for the remaining nine items was .8543 indicating that all of the items are measuring the same thing. The factor analysis with varimax rotation revealed that these items were loading on only one factor and all of the factor loadings were between .629 and .760. The individual items were then added together to create a composite "role confusion" measure for the remaining analyses. The scores for this scale ranged from zero to twenty-nine. Higher scores indicate respondent's reporting a higher frequency of problems with role confusion by their peers. The skewness and kurtosis statistics indicate the scale is close to being normally distributed and does not require any transformations.

The “client diffusion” scale was initially comprised of five survey questions (please refer to Table 4). After preliminary analysis, item 21 was dropped because it seemed to be not relevant to a sample consisting of mostly master's level therapists. The reliability analysis performed on the remaining four items produced a Cronbach’s Alpha of .6974. The factor analysis with varimax rotation extracted only one factor with the 
individual factor loadings being between .688 and .802. These individual items were added together to produce a composite "client diffusion" scale for the remaining analyses. The scores for this scale ranged from zero to fifteen. Again, higher scores indicate respondent's reported higher frequency of problems with client diffusion by peers. The skewness and kurtosis statistics indicate the scale is close to normally distributed and does not require any transformations.

The "unintentional witnessing" scale was originally comprised of five items (please refer to Table 5). After a review of the items, it was decided that two items originally included on the confidentiality measure would be included with the unintentional witnessing (items $7 \& 20$ ). The complete seven items together produced a Cronbach's Alpha of .9099 indicating the items are measuring the same thing. The subsequent factor analysis with varimax rotation resulted in one factor being extracted with the individual factor loadings being between .651 and .884 . The scores for the scale range from zero to eighteen. Like above, higher scores indicate respondent's reporting a higher frequency of problems with unintentional witnessing by their peers.

\section{Tests of Research Questions}

The first research question, ("Will therapists (both in-home and outpatient) who have had a specific course on ethics in their masters or doctoral training report significantly different ethical concerns for people in their position compared with therapists that did not have such a course?”), was examined using an independent sample difference of means test. 79 of the respondents (81.4\%) reported they had completed an

ethics course as part of their graduate program. There were no significant differences on 
any of the ethical dimensions based on having completed the ethics course (please refer to Table 6)

For the confidentiality scale, those who had completed an ethics course had a mean score of 5.93 while those who had not had a mean score of 7.25. With the client diffusion scale, those who had completed an ethics course had a mean score of 5.93 while those who had not had a mean score of 6.39. On the role confusion scale, those who had completed an ethics course had a mean score of 11.08 while those who had not had a mean score of 12.18. Finally, for the unintentional witnessing scale, those who had completed an ethics course had a mean score of 8.08 while those who had not had a mean score of 8.22. While none of these difference in means tests were statistically significant, it is interesting to note that those who had completed an ethics course reported lower average scores on each of the ethical dimensions.

The second research question, ("Will therapists (both in-home and outpatient) who are state licensed report significantly different ethical concerns for people in their position than those therapists who are not state licensed?”), also used an independent sample difference of means tests for the analysis (please refer to Table 7). 37 of the respondents (38.1\%) reported being state licensed. On the confidentiality scale, those who were state licensed had a mean score of 5.58 while those who were not had a mean score of 6.54. For the client diffusion scale, those who were state licensed had a mean score of 5.32 while those who were not had a mean score of 6.45 . With the role confusion scale, those who were state licensed had a mean score of 9.95 while those who were not had a mean score of 12.12. Finally, on the unintentional witnessing scale, those who were state licensed had a mean score of 7.86 while those who were not had a mean 
score of 8.25. Like the previous results, the difference of means tests were not statistically significant.

The third research question, ("will in-home therapists report participating in a significantly different amount of structured monthly supervision than their office-based, outpatient counterparts?”), was analyzed using an independent sample difference of means test (please refer to Table 8). All of the supervision items had the same frequency response set [i.e., (0) Never, (1) Once or twice a year, (2) Quarterly/ 4 times a year, (3) Every other month, (4) Monthly, (5) Every other week, (6) Once a week, (7) More than once a week]. There was not a statistically significant difference between in-office and home-based therapists in their reports of frequency of receiving group supervision (mean in-office $=4.22$, mean home-based $=3.74)$. However, there was statistically significant difference between the two types of therapists in terms of their reports of receiving individual supervision, receiving clinical consultation from a colleague in the field, and keeping information from a supervisor. Office-based therapists reported receiving individual supervision significantly more frequently $($ mean $=4.76)$ than their home-based counterparts $($ mean $=3.64)(p=.011)$. Likewise, office-based therapists reported receiving clinical consultation from a colleague in the field significantly more often $($ mean $=4.97)$ than their home-based counterparts $($ mean $=3.86)(p=.010)$. Conversely, home-based therapists reported keeping information from their supervision significantly more frequently $($ mean $=.55)$ than their in-office counterparts $($ mean $=.08)(p=.033)$. There were no statistically significant differences between in-office and home-based therapists on the remaining supervision items.

The fourth research question, (will the more years of experience that one has in a specific setting (whether in-home, office-based, or mixed) show significantly different 
uses of weekly supervision by a trained colleague?), used a one-way analysis of variance for the analysis (please refer to Table 9). Respondents were asked to report how many years they had worked as a therapist [i.e, (0) Less than 1 year, (1) More than 1 year, but less than 2 years, (2) More than 2 years, but less than 5 years, (3) More than 5 years, but less than 10 years, (4) More than 10 years, but less than 20 years, (5) 20 years or more]. As stated above, almost $60 \%$ of the respondents reported working less than five years as a therapist. There were no statistically significant differences between the years worked as a therapist and receiving group supervision $(\mathrm{F}=.687, \mathrm{p}=.634)$, receiving individual supervision $(\mathrm{F}=.901, \mathrm{p}=.484)$, or receiving clinical consultation from a colleague in the field $(\mathrm{F}=1.84, \mathrm{p}=.113)$. In fact, the only supervision variable that was significant with the years worked as a therapist factor is seeking advise on mandatory reporting laws in regard to observed child abuse and/or neglect $(\mathrm{F}=2.649, \mathrm{p}=.028)$. This indicates difference in years worked as a therapist has an effect on the respondent's reporting of seeking advice for observed child abuse or neglect. The mean overall score for this item was 1.06. Therapists in categories three (mean $=1.59)$ and five (1.83) reported seeking this type of advise more often than the overall mean, while those therapists in categories $0($ mean $=.50)$, two $($ mean $=.96)$ and four $($ mean $=.50)$ reported seeking this advice less often. Thus, there was not a clear, significant pattern in terms of length of time working as a therapist and seeking advice on mandatory reporting of observed child abuse and/or neglect.

The fifth and final research question examines whether the different types of therapists (in-office, home-based) report different ethical violations by their peers. Preliminary analysis using an independent sample difference of means test showed significant differences between in-home and office-based therapist's reports of peers 
ethical violations (please refer to Table 10). For the confidentiality scale, the in-home therapists reported a significantly higher frequency of perceived violations by their peers $($ mean $=7.18)$ than their office-based counterparts $($ mean $=4.73, \mathrm{p}=.003)$. Similarly, with the role confusion scale, the in-home therapists reported a significantly higher frequency of perceived violations by their peers (mean $=12.40$ ) than their office-based counterparts $($ mean $=9.67)(p=.04)$. The client diffusion scale was close to reaching statistical significance $(\mathrm{p}=.058)$, with the in-home therapists reporting perceived violations by their peers more frequently $($ mean $=6.62)$ than their office-based counterparts $($ mean $=5.24)$. The last ethical dimension (i.e., unintentional witnessing) was not statistically significant between the two types of therapists (in-home mean $=$ 7.80; office-based mean $=8.57 ; \mathrm{p}=.458)$.

There was some concern that the two types of therapists may differ substantially on a number of dimensions (i.e., level of education, years of working as a therapist, gender, completing an ethics course, state licensure). To examine this, independent sample difference of means tests were run (please refer to Table 11). These tests revealed that only state licensure [coded (0) yes, (1) no] was statistically significant with in-office therapists reporting being currently licensed by the state (mean $=.41$ ) more than their home-based counterparts (mean $=.74$ ). Since there was a difference between the two groups in terms of being currently licensed by the state, the final analyses will utilize multiple regression in order to account for the difference.

The first regression model examines the effects of position type and current state licensure on the confidentiality scale (please refer to Table 12). The model as a whole is statistically significant $(\mathrm{F}=4.552, \mathrm{p}=.013)$. The position type variable $[$ coded $(0)=$ inhome, (1) office-based] reaches a high degree of statistical significance $(t=-2.652, p=$ 
.01 ), while the current state licensure variable is not statistically significant. The independent variables together account for $9.5 \%$ of the variance. The unstandardized regression of -2.330 indicates an inverse relationship between the position type variable and the confidentiality scale. In other words, in-home therapists report significantly fewer instances of confidentiality breeches by their peers than their home-based counterparts.

The second regression model examines the effects of position type and current state licensure on the role confusion scale (please refer to Table 13). Here, the model as a whole is close to being statistically significant $(\mathrm{F}=2.816, \mathrm{p}=.065)$. Neither of the two independent variables were statistically significant. This indicates that the in-home and office-based therapists reported problems with role confusion by their peers equally after controlling for state licensure.

The third regression model examines the effects of position type and current state licensure on the on the client diffusion scale (please refer to Table 14). Like the previous model, this one is also close to reaching statistical significance $(F=2.519, \mathrm{p}=.086)$. Again, neither of the two indepdent variables reaches statistical significance. This indicates that after controlling for state licensure, the two therapists were similar in their reports of client diffusion violations by their peers.

The final regression model examines the effects of position type and current state licensure on the unintentional witnessing scale (please refer to Table 15). The results indicate that the model as a whole is not statistically significant $(F=.514, \mathrm{p}=.600)$. Neither the position type nor the current state licensure variables were statistically significant indicating that there were no differences in reporting unintentional witnessing between the two types of therapists. 


\section{CHAPTER FOUR DISCUSSION \& CONCLUSION}

This chapter provides a discussion of the findings as they relate to each of the five questions asked by this research. In addition, consideration of the survey instrument, future directions for continued research, and limitations of this study are also explored.

The first research question addressed potential differences between in-home and office-based therapist's perceptions across the four ethical dimensions of confidentiality, role confusion, client diffusion, and unintentional witnessing in relation to structured ethical training. The second question considered the implications of being state licensed and perceptions across the four ethical dimensions between in-home and office-based therapists. The third question considered the amount of structured supervision occurring across multiple dimensions with in-home and office-based therapists. In addition, whether or not each position type reported differences in asking for assistance from clinical supervisors was considered. The fourth question considered whether experience in either position (in-home or office-based) was indicative of utilizing significantly different uses of supervision by a trained colleague. The fifth and final question asked whether there would be a difference between in-home and office-based therapists in their perceptions of ethical concerns across the four dimensions of confidentiality, role confusion, client diffusion, and unintentional witnessing. In this final question, the two position-types were compared across a number of individualistic characteristics such as state licensure, age, gender, years of experience, race, education, theoretical orientation, and years at position. 


\section{Question \#1:}

While none of the difference in means tests were statistically significant in regards to formalized ethics training, it is interesting to note that those who had completed an ethics course reported lower average scores on each of the ethical dimensions. This tendency was strongest in regards to confidentiality dimensions with those that had taken an ethics course as compared to those that did not have an ethics course. This is in keeping with the current literature (Gross \& Robinson, 1987) as the two largest areas of disparity between those that have ethical training as compared to those that do not often stem from problems with confidentiality and role confusion. In the future, it may be helpful to incorporate additional confidentiality questions that may help bolster significance and create a more robust factor construct.

Question \#2:

When considering the impact of licensing between the two kinds of therapists, a similar situation arose. There were disparities in the difference of means tests between those therapists that were licensed by the state in their given degree, as opposed to those that were not licensed. Those that were not licensed described higher rates of perceived ethical violations by their like-employed peers. Again, though this was not determined to be significant, it warrants continued exploration. These tendencies are in keeping with the current literature (Lamb \& Cutuzarmo, 1998; Kitchener \& Anderson, 2002; and (Gottleib et al., 1993), which highlights the complications of understanding the defined nature of roles and the accompanying boundary violations. 
Question \#3:

In addition to examining the perceptions in the field of therapy in regards to ethical dilemmas faced by outpatient and in-home therapists, there was also special focus paid to supervision differences between the two groups. Unlike the ethical question section, which used proxy measures, the supervision questions were more straightforward and asked each participant to describe their individual experiences with supervision. Though many items did not show a significant difference between the two groups, several other items did. Office-based therapists reported significantly higher rates of obtaining individual supervision and receiving consultation advice from a colleague in the field. As described earlier, in-home therapists often utilize structured group supervision for most of their clinical direction. Some might argue that in-home therapists received the majority to their clinical supervision in this group format, and so they are just as prepared to deal with their caseloads. The problem with this supposition is that office-based therapists not only received higher levels of individual supervision, but higher levels of group supervision as well. This difference is not significant in a statistical sense, but it does allude to the concerns that in-home therapists are by in large not gaining the same amount of supportive consultation as their office-based peers.

This is important for several reasons according the current literature. There is tremendous variation in overall training between disciplines and in-home therapy’s traditional use of group supervision at the exclusion of individual support may be creating a false sense of adequate, targeted supervisory experience. Add this to research that has addressed the issue that many supervisees see their office-based supervisors as being out-of-touch with their experiences in the field (Plante, 1999), and what emerges is 
a more secretive supervisee-supervisor relationship that meets less frequently and is less likely to address individual issues associated with ethical constraints.

Findings in this survey found that home-based therapists reported that they were significantly more likely to keep information from their supervisors than their officebased counterparts and were significantly less likely to use peer consultation. These items highlight a serious concern in the field that will require additional research. As home-based therapists are already less observed in a proximal sense when compared to their office-based peers, it should be disconcerting to supervisors that are putting their clinical license on the line, and who are ultimately responsible for the clients in question, that their supervisees may be keeping key pieces of information hidden. It will be essential for future research to examine the nature of these withholdings as many questions remain as to the why an in-home therapist would be less likely to divulge information. One might conjecture that the in-home therapist would feel that the environmental differences would make some therapeutic interventions inconsequential, but one might also wish to determine if these withholdings are due in part to ethical breaches that may be more likely to occur in the clients' home settings. Additionally, the fact that in-home therapists show significantly reduced amounts of using peer consultation is a further concern, as this sort of collaboration is often addressed in the literature as being essential for maintaining ethical standards and maintaining proper guidance in the field (Deutsch, 1985).

Question \#4:

When examining the nature of years worked as a therapist and supervision obtained, this study was heavily weighted to those that have worked for less than 5 years 
in the field. With $60 \%$ of the sample being relatively new to the field of therapy, it was not surprising that there were virtually no items of significance in regards to this question. Less seasoned therapists did report seeking more information from their supervisors in regards to mandatory observed child abuse reporting laws. This finding is not surprising as mandatory reporting laws are often complicated legal and systemic issues that are not easily navigated by therapists. Additionally, it has been well documented (Pope \& Bajt, 1998) that varying therapeutic theoretical models take decidedly different stands on when and how a client's caregiver should be reported for these kinds of behaviors.

Question \#5:

As expected, there were differences in the perceived ethical dilemmas occurring in the field by in-home therapists when compared to traditional office-based therapists. Specifically, in the ethical arenas of confidentiality and role confusion, there were significant perceived differences between in-home and office-based positions. Pope \& Vetter (1992) described confidentiality breaches to be the most common dilemma faced by therapists. Additionally, the work of Schank \& Skovholt (1997) explained the issues inherent in confidentiality breaches when there is a greater intersection of clients in the community as found in in-home, MST work.

One need only consider the nature of each position and the uncontrolled environmental factors that play into the work of the in-home therapist to gain an understanding of these differences. Likewise, in reviewing the guidelines set forth by Kitchener, there is established precedent to understand why in-home therapists would 
perceive greater ethical dilemmas in regards to role confusion. The in-home therapist is likely at higher risk for 1) incompatibility of expectations between roles, 2) divergence of obligations of different roles, and 3) difference of power and prestige between the professional and client (Kitchener, 1998).

This study offers preliminary data in regards to the impact of potential ethical quandaries associated with confidentiality and role confusion as they apply to in-home therapists. It is not surprising that in-home therapists may encounter higher perceived rates of these types of dilemmas due to the nature of the extended environment where they provide therapy (i.e., home, school, community, etc.).

The ability to maintain a therapeutic posture while in someone’s home surely has an affect on the ability to maintain strict ethical guidelines in these two spectrums of consideration. Furthermore, client diffusion showed a strong tendency toward significance and may be worthy of future study. It is possible that the ideas supporting the client diffusion construct are problematic for both types of therapists, and that this phenomenon has not been adequately studied at this time.

The results of the unintentional witnessing scale were somewhat surprising as there was no significant difference between the two types of therapists, but there seemed to be a greater instance of perceived problems in this category by all respondents than what was expected initially. This is uncharted territory even though mandatory reporting of child abuse is an issue of existing research. As described earlier, current research has demonstrated that therapists are more likely to ignore laws of mandatory reporting if they feel that it will interfere with other established goals in the therapeutic process or be detrimental to rapport building (Koocher \& Keith Spiegel, 1990; Pope \& Bajt, 1998). 
Many of the other questions that were identified on the survey as belonging to the unintentional witnessing scale had higher mean scores attached to those working in the office setting than those in the home. In many ways this is a surprising find, as this study hypothesized that the proximal nature of the in-home therapist to the target client within their home living space would lead to a higher perceived rate of unintentional witnessing dilemmas/ higher observations of criminal activity. With office-based therapists having an overall higher mean score in regards to those factors associated with unintentional witnessing, some of the previous research that has alluded to the secretive nature of these ethical concerns in the office environment are again brought to light (Nicolai \& Scott, 1994; Emery \& Laumann-Billings , 1998).

These findings may be explained by considering the possibility that in-home therapists are underreporting what they find to be troubling in these categories due to their immersion in the communities and homes of their specified client, and/or there may be a higher instance of individuals sharing aspects of criminal behavior with their therapists when they are in the "protective" confines of the office environment with its regulated boundaries of confidentiality and privacy. As there were no significant differences determined between either in-home or office-based therapists, all therapists may benefit from increased education on these types of situations depending on their clientele.

\section{Comments on the Survey}

Responses to the survey covered a spectrum of reactions both positive and negative in nature. Some responses were general and supportive such as "Good work" 
and "Best of Luck". One therapist stated that she was "excited to see that someone is looking into the ethical aspects of the MH/MR system”.

Other respondents addressed specific areas of concern and the necessity of this type of research (especially as it relates to in-home therapy). Comments included, "Glad to know someone out there asks good questions that needed to be addressed. I know I feel better." Another therapist stated the stresses of maintaining confidentiality when one carries documents around, "especially when you do not have an office and are on the road $15 \%$ of the time”. Still another commented on her situation in supervision as an in-home therapist with an office-based supervisor stating "our supervisor does not give realistic, practical”. A supervisor of a wraparound, MST program stated, “There is minimum supervision in this field, which is always a concern for everyone involved”.

Several therapists offered critical feedback, with some addressing the survey itself and others the overall purpose of the questions asked. Such criticisms included: "It would have been helpful to answer these questions if they were separated into homebased vs. office based" and "There should be some sort of compensation or draw-in enhancement for completing the survey”. One therapist addressed the need to have questions related to fraudulent billing as it is "seen everyday without recourse from the higher ups who don’t care”. Another discouraged therapist stated that he has “seen many unethical behaviors by therapists in regards to boundaries, billing, and client's overall needs.”

Another therapist rightly stated that the term “direct evidence” in regards to the mandatory reporting questions on child abuse were confusing and may have been better worded as "visible evidence vs. verbal statements". Supporting the need for continued research in this arena, one supervisor of an intensive in-home counseling program stated 
that "many of these things are expected". One advised that having another choice between “once a year” and "never”, such as "several times a career” may have been helpful in gaining more accurate frequency data. Still others added, "It was difficult to answer questions about other colleagues because we are isolated in this position (inhome). Finally, one Ph.D. stated that she had concerns over the use of proxy measures in this study to determine the potential ethical dilemmas in the field and said, "Why not just ask therapists if they’ve done these things, anonymously of course!”

\section{Limitations of the Study}

Several limitations to this study are worth considering. The study relied on selfreport data, which pervious research has shown to be somewhat confounding (Pomerantz, 2001). Due to the nature of this study, convenience sampling was utilized that directed mailings to therapists' places of employment. Clinical supervisors were instructed to pass the sealed packets out to therapists via their mail boxes at work. Even though every effort has been made to assure the respondent that anonymity and confidentiality would be maintained, it is difficult to discern the level of perceived threat experienced by therapists who were addressing these ethical issues in their work settings. There may have been widespread discrepancies in the distribution process of the surveys at work that may have affected return rates (i.e.: Were survey distribution protocols followed as instructed? Were directors pro or con in their perception of the research?).

Section II of the study examined ethical perceptions in the field according to the four ethical dimensions of confidentiality, role confusion, client diffusion, and unintentional witnessing. These questions utilized proxy measures to both allow for 
additional protection and confidentiality in regards to answering highly sensitive questions, but also to gain a general idea of how therapists view the occupational "terrain" of their given positions. Ethical behaviors are often preceded by perceptions of what are not only the acceptable upheld standards, but what are the normative practices of others doing similar work in the field.

Given the use of proxy measures (commenting on others' behaviors, not one’s own), consideration must be made in regards to the limitations of this sort of inquiry. First of all, therapists are commenting on perceptions that may or may not be the actual reality of their occupational conditions. Second, answers to Section II may be affected by the level which a respondent is privy to their co-workers' therapeutic and ethical behaviors. Several surveys mentioned difficulties in assessing what their colleagues were practicing, and this seemed to be more concentrated with the office-based therapists. Newer employees may be less able to assess the normative practices in their peers, and as the overwhelming majority of respondents were in the field for less than five years (60\% of sample), the ability to identify ethical deviations may be less honed.

Despite a sizeable mailing of 480 disseminated packets, the return rate was quite meager (20.2\% or 97 returned surveys). This is particularly confounding as surveys that are sent to professionals with the intention of bolstering the research in a given field often have higher return rates (Groves et al., 1992). This did not hold true for this survey and it is worth noting that future research may be better served if the survey is of a singular nature (ethics or supervision, rather than both). Several respondents commented on the lack of incentives and the length of the survey. It may also be of concern that the surveys were distributed through people's workplaces and that the sensitive nature of the questions were consider career-threatening. As other surveys have covered similar 
material and yielded higher rates of return, it is possible that convenience sampling affected the final count. One final consideration regarding the low return-rate is that many of the respondents stem from divergent educational backgrounds that might limit the ability to connect with the research through a shared discipline or common ethical training.

This survey attempted to capture baseline data on a wide-array of behaviors that may be complex and extend beyond the definitions expressed in this survey. In this, through factor analysis, many of the constructs in this survey are not well-defined. The literature struggles with what is considered a boundary violation and the nature of role confusion in the profession. Likewise, the areas of client diffusion and unintentional witnessing have had scarce consideration in prior research. It is important to remember that this survey is a preliminary investigation and that future research should build upon, as well as continually define these constructs. In analysis of these items under the four proposed ethical dimensions, it became apparent that some of the questions were loading on a separate factor, which was not originally considered. The confidentiality scale items showed particular problems as many questions fell under mandatory reporting considerations and hence, were better attributed to the criminality aspects of the unintentional witnessing scale.

The definition of the independent variable of role confusion seems to pose some limitations, as several questions may not have taken into account theoretical differences in regards to improving client systems. Future research should consider differences between system-based therapeutic interventions as compared to time spent with individuals that do nothing to enhance or improve functioning in the specified client. 


\section{Future Research}

At this time it may be pertinent to consider implications for future research that has yet to be discussed. It seems clear from this study that there are some rising research areas that could use additional inquiry. Specifically, more research should be directed at differentiating the types of confidentiality and role confusions that are occurring within the in-home therapeutic environments. It is not surprising that in-home therapists attributed higher perceived ethical quandaries in those two arenas, as they are not in a controlled setting. What may prove interesting is which questions need to be addressed specifically. Which kinds of confidentiality and boundary issues created by role confusions are most relevant to in-home work? How might education, experience, and supervision differences alter actual ethical violations by in-home therapist? The word actual is used intentionally here, as a survey that addresses behavioral issues of in-home therapists without the use of proxy measures is the logical next step.

Additional needs for future research exist in how each therapist self selects for the given type of therapeutic position. Home-based therapists were significantly less likely to be licensed by the state. State licensure may have unifying properties both through the nature of the members that prescribe to a given code of standards and expectations, as well as a base knowledge on key issues in the field that must be navigated through via the licensing exam. One might posit that increased difficulties with not only professional identity, but the nature and purpose of collective ethical practices may be less tangible to those that remain unlicensed.

Perhaps the most important consideration for future research emerges through the supervision questions in this study. It is striking that individual supervision is lacking with those doing in-home work. It is also of concern that home-based therapists are far 
more likely to keep information from their supervisors. Research that is directed at this phenomenon may prove a great boon to supervisors that are directing wraparound, MSTstyle programs, and who believe they are getting similar disclosures from their in-home and office-based supervisees. There are questions as to which types of information are being withheld, are they ethical violation issues, and do certain clients engender greater levels of these kinds of withholdings? All would be worthy avenues of additional discourse and study.

Finally, it seems that therapists are encountering surprisingly high degrees of criminality disclosures in their sessions as per questions related to the unintentional witnessing dimension. It was surprising to note that office-based therapy accounted for even higher levels of such perceived disclosures based on means comparisons. As this area of inquiry has been largely limited to mandatory reporting laws, it may prove relevant to investigate the types of criminal activities that therapists are encountering, as well as their reactions to such revelations in the home and office settings. Regardless, this is an area that should be addressed by future research to determine if therapists are obtaining the necessary ethical and supervisory guidance when it comes to issues that have such criminality components. 


\section{REFERENCES}

Alwin, D.F., \& Krosnick, J.A. (1989). The measurement of values in surveys: a comparison of ratings and rankings. In E. Singer \& S. Presser (eds.). Survey Research Methods: A Reader. Chicago: University of Chicago Press.

American Psychological Association (2002). Ethical principles of psychologists and code of conduct. Available online from www.apa.org/ethics/

Babbie, E. (1990). Survey Research Methods. Belmont, California: Wadsworth Publishing.

Baird, K.A., \& Rupert, P.A. (1987). Clinical management of confidentiality: s survey of psychologists in seven states. Professional Psychology: Research and Practice, 18, 347-352.

Barnett, J. (1998). Sensitive questions and response effects: an evaluation. Journal of Managerial Psychology, 13 (1/2), 63-76.

Bennett, B. (1997, March). Risk management workshop. California Psychological Association State Convention, San Jose, Ca.

Berry, W.D., \& Feldman, S. (1985). Multiple Regression in Practice. California, Sage Publications.

Borduin, C.M., Mann, B.J., Cone, L.T., Henggeler, S.W., Fucci, B.R.. Blaske, D.M. \& Williams, R.A. (1995). Multisystemic treatment of serious juvenile offenders: Long term prevention of criminality and violence. Journal of Consulting and Clinical Psychology, 63, p. 569-578.

Bradburn, N.M., Sudman, S., Blair, E. \& Stocking, C. (1989). Question threat and response bias (pp. 371-384). In E. Singer \& S. Presser (Eds.). Survey Research Methods: A Reader. Chicago: University of Chicago Press.

Bronfenbrenner, U. (1979). The ecology of human development: experiments by nature and design. Cambridge, MA: Harvard University Press.

Burchard, J., Burchard, S., Sewell, R., \& VanDenberg, J. (1993). One kid at a time: evaluative case studies and description of the Alaska Youth Initiative Demonstration Project. Juneau (AK): State of Alaska, Division of Mental Health and Mental Retardation.

Campbell, C.D., \& Gordon, M.C. (2003). Acknowledging the inevitable: Understanding multiple relationships in rural practice. Professional Psychology: Research and Practice, 34, 430-434.

Caudill, O.B., \& Pope, K.S. (1995). Law and mental health professionals: California. Washington, DC: APA. 
Crino, M.D., Rubenfeld, S.A., 7 Willoughby, F.W. (1985). The random response technique of as an indicator of questionnaire item and social desirability/personal sensitivity. Education and Psychology Measurement, 45, 453-468.

Crowe, M., Grogan, J., Jacobs, R., Lindsey, C., \& Mark, M. (1985). Delineation of the roles of clinical psychology. Professional Psychology: Research and Practice, $16,124-137$.

Cunningham, P.B., \& Henggeler, S.W. (1999). Engaging multiproblem families in treatment: Lessons learned through the development of multisystemic therapy. Family Process, 38, 265-281.

Curtis, C.M., Ronan, K.R., \& Borduin, C.M. (2004). Multisystemic treatment: a metaanalysis of outcome studies. Journal of Family Psychology, 18 (3), p. 411-419.

Delaronde, S., King, G., Bendel, R., \& Reece, R. (2000). Opinions among mandated reporters toward child maltreatment reporting policies. Child Abuse and Neglect, 24 (7), 901-910.

Deutsch, C. (1985). A survey of therapists' personal problems and treatment. Professional Psychology: Research and Practice, 23, 211-215.

DeVellis, R. F. (2003). Scale Development: Theory and Applications. Sage Publications: Thousand Oaks, CA.

Dillman, D.A. (1991). The design and administration of mail surveys. Annual Review of Sociology, 17, 225-249.

Dillman, D.A. (1983). Mail and self-administration surveys. In Peter H. Rossi, James D. Wright, and Andy B. Anderson (eds.). Handbook of Survey Research. 10: 359377.

Eber, L., Sugai, G., Smith, C.R., \& Scott, T.M. (2002). Wraparound and positive behavioral interventions and supports in the schools. Journal of Emotional and Behavioral Disorders, 10(3), 71-180.

Egan, M., \& Kadushin, G. (1999). The social worker in the emerging field of home care: Professional activities and ethical concerns. Health and Social Work, 24 (1), 4355.

Emery, R.E., \& Laumann-Billings, L. (1998). An overview of the nature, causes and consequences of abusive family relationships. American Psychologist, 53, 121135.

Epstein, R.S., Simon, R.I. (1992). Assessing boundary violations in psychotherapy: survey results with the exploitation index. Bulletin of the Menninger Clinic. 56(2), 150-167. 
Epstein, R.S. (1994). Keeping boundaries: maintaining safety and integrity in the psychotherapeutic process. Washington, DC: American Psychiatric Press.

Farmer, M.Z., Dorsey, S., \& Mustillo, S.A. (2004) Intensive home and community interventions. Child and Adolescent Psychiatric Clinics of North America, 13, p. 857-884.

Feather, N.T. (1973). The measurement of values: effects of different assessment procedures. Australian Journal of Psychology, 25, 221-231.

Fine, M. \& Turner, J. (1991). Tyranny and freedom: looking at ideas in the practice of family therapy. Family Process, 30, 307-320.

Finkelhor, D., \& Zellman, G.L. (1991). Flexible reporting options for skilled child abuse. Child Abuse \& Neglect, 15(4), 335-341.

Fischer, H. (1999). Exemptions from child abuse reporting. American Psychologist, 54(2), 145.

Fowler, F.J. (2002). Survey Research Methods: Third Edition. Thousand Oaks, CA: Sage Publications.

Gawthrop, J.C., \& Uhlemann, M.R. (1992). Effects of problem-solving approach in ethics training. Professional Psychology: Research and Practice, 23 (1), 38-42.

Goldsein, E.G. (1997). To tell or not to tell: the disclosure of events in the therapists' life to the patient. Clinical Social Work Journal , 25, 41-58.

Goldstein, E.G. (1994). Self-disclosure in treatment: what therapists do and don't talk about. Clinical Social Work Journal, 22, 417-433.

Gross, D.R., \& Robinson, S.E.(1987). Ethics in counseling: A multiple role perspective. TACD Journal, 15, 5-15.

Grosser, \& Paul, (1964). Ethical issues in family group therapy. American Journal of Orthopsychiatry, 34, 875-884.

Groves, R.M., Cialdi, R.B., \& Couper, M.P. (1992). Understanding the decision to participate in a survey. Public Opinion Quarterly, 56, 475-495.

Hare-Mustin, R. (1980). Family therapy may be dangerous for your health. Professional Psychology, 11, p. 935-938

Henggeler, S.W., Rowland, M., Halliday-Boykins, C., Sheidow, A.J., Ward, D.M., \& Randall, J. (2003). One year follow-up of multisystemic therapy as an alternative to the hospitalization of youths in psychiatric crisis. Journal of American Academy of Child and Adolescent Psychiatry, 42(5), p. 443-551. 
Henggeler, S.W., Schoenwald, S.K., Liao, J.G., Letourneau, E.J., \& Edwards, D.L. (2002). Transporting efficacious treatments to field settings: The link between supervisory practices and therapist fidelity in MST programs. Journal of Clinical Child Psychology, 31(2), 155-167.

Henggeler, S.W., Schoenwald, S.K., Borduin, C.M., Rowland, M.D., \& Cunningham, P.B. (1998). Multisystemic treatment of antisocial behavior in children and adolescents. New York: Guilford Press.

Henggeler, S.W., \& Schoenwald, S.K. (1998). The MST supervisory manual: Promoting quality assurance at the clinical level. Charleston, SC: MST Institute.

Henggeler, S.W., Schoenwald, S.K., Pickrel, S.G. (1995). Multisystemic therapy: Bridging the gap between university and community based treatment. Journal of Consulting and Clinical Psychology, 63, 709-717.

Horst , E.A. (1989). Dual relationships between psychologists and clients in rural and urban settings. Journal of or Rural Community Psychology, 10 (2), 15-25.

Huey, S.J., Henggler, S.W., Brondino, M.J., and Pickrel, S.G. (2000). Mechanisms of change in multisystemic therapy: reducing delinquent behavior through therapist adherence and improved family and peer functioning. Journal of Consulting and Clinical Psychology, 68, 451-467.

Huffine, C. (2002). Current trends in the community treatment of seriously disturbed youths. Psychiatric Services, 53 (7), 809-811.

James, J.M. (1990). Effect of monetary incentives and follow-up on the response rate and response and response quality in mail surveys. Public Opinion Quarterly, 54, 139-142.

Jennings, F.L. (1992). Ethics of rural practice. Psychotherapy in Private Practice, 10, 85-104.

Kazdin, A.E. (1990). Premature termination from treatment among children referred for antisocial behavior. Journal of Child Psychology and Psychiatry, 31, 415-425.

Kennel, R.G. (1997). Factors influencing psychologists’ reporting of child sexual abuse: gender, age, and theoretical orientation. Dissertation Abstracts International: Section B: The Science and Engineering, 57 (12-B), p. 7732.

Kitchener, K.S. (1988). Dual Role relationships: what makes them so problematic? Journal of Counseling and Development, 67, 217-221.

Koocher, G.P., \& Keith-Spiegel, P. (1998). Ethics in psychology: Professional standards and cases. New York: Oxford University Press. 
Koocher, G.P., \& Keith-Spiegel, P. (1990). Children, ethics, and the law: Professional issues and cases. Lincoln: University of Nebraska Press.

Lakin, M. (1994). Morality in group and family therapies: multiperson therapies and the 1992 ethics code. Professional Psychology: Research and Practice, 25(4), 344348.

Lazarus, A.A. (1994a). How certain boundaries and ethics diminish the therapeutic effectiveness. Ethics and Behavior, 4, 255-261.

Lazarus, A.A. (2002). Dual relationships and psychotherapy. New York, NY: Springer.

Lee, R.M. (1993). Doing Research on Sensitive Topics. London: Sage.

Lindenthal, J.J., Jordan, T.J., Lentz, J.D., \& Thomas, C.S. (1998). Social workers' management of confidentiality. Social Work, 33, 157-158.

Malysiak, R. (1998). Deciphering the Tower of Babel. Journal of Child and Family Studies, 7 (1), 11-25.

Margolin, G., Chien, D., Duman, S.E, Fauchier, A.G., Elana, B., Ramos, M.C., Vickerman, K. A., Oliver, P. H. (2005). Ethical Issues in Couple and Family Research. Journal of Family Psychology, 19 (1), 157-167

Martinez, R. (2000). A model for boundary dilemmas: Ethical decision-making in the patient-professional relationship. Ethical and Human Science and Services, 3, 4361.

Miller, R.D., Maier G.J. (2002). Nonsexual boundary violations: sauce for the gander. Journal of Psychiatry and Law, 30(3), 309-329.

Minuchin, P. (1985). Families and individual development: Provocations from the field of family therapy. Child Development, 56(2), 289-302.

Mullen, P.D., Easling, I., Nixon, S.A., Koester, D.R., Bidel, A.K. (1987). The cost effectiveness of randomized incentive and follow-up contacts in a national mail survey of family physicians. Evaluation of Health Professions, 10, 232-245.

Nederhof, A.J. (1983a). Effects of repetition and consistency of personalization treatments on response rate in mail surveys. Social Science, 12, 1-9.

Nicolai, K.M. \& Norman, S.A. (1994). Provision of confidentiality information and its relation to child abuse reporting. Professional Psychology: Research and Practice, 25(2), 154-160.

Papouchis, N. (1990). Self-disclosure and psychotherapy with children and adolescents. In G. Shicker \& M. Fischer (eds.). Self-disclosure in the therapeutic relationship (p. 157-174). New York: Plenum. 
Patten, C., Barnett, T., \& Houlihan, D. (1991). Ethics in marital and family therapy: A review of the literature. Professional Psychology: Research and Practice, 22(2), 171-175.

Peterson, M.B. (2001). Recognizing concerns about how some licensing boards are treating psychologists. Professional Psychology: Research and Practice, 32(4), 339-340.

Plante, T.G. (1999). Ten strategies for psychology trainees and practicing psychologists interested in avoiding ethical and legal perils. Psychotherapy, 36 (4), 398-403.

Pope, K.S., \& Bajt, T.R. (1988). When laws and values conflict: A dilemma for psychologists. American Psychologist, 43, 828.

Pope, K.S. \& Garcia-Peltoniemi, R.E. (1991). Responding to victims of torture: Clinical issues, professional responsibilities, and useful resources. Professional Psychology: Research and Practice, 22, 269-276.

Pope, K.S., Tabachnick, B.G., \& Keith-Spiegel, P. (1987). Ethics of practice: the beliefs and behaviors of psychologists as therapists. American Psychologist, 42, 9931006.

Pope, K.S. \& Vetter, V.A. (1992). Ethical dilemmas encountered by members of the American Psychological Association: a national survey. American Psychologist, 47, 397-411.

Pomerantz, A., Ross, M.J., Gfeller, J.D., \& Hughes, H. (1998). Ethical beliefs of psychotherapists: Scientific findings. Journal of Contemporary Psychotherapy, 28 (1), 35-43.

Prinz, R.J., \& Miller, G.E. (1996). Parental engagement in interventions for children at risk for conduct disorder (pp. 161-183). In R. DeV. Peters, \& R.J. McMahon (eds.), Preventing childhood disorders, substance abuse, and delinquency. Thousand Oaks CA: Sage Publications.

Roberts, M.L. \& Hite, P. (1990). Unpublished report of a nation-wide survey of 900 households. University of Alabama.

Rosenblatt, A. (1996). Bows and ribbon, tape and twine: wrapping the wraparound process for children with multi-system needs. Journal of Child and Family Studies, 5(1), 101-117.

Schaeffer, C.M., \& Borduin, C.M. (2003). Moderators and mediators of therapeutic change in multisystemic treatment of serious juvenile offenders. Unpublished manuscript. 
Schank, J.A., Skovolt, T.M. (1996). Dual relationship dilemmas of rural and small community psychologists. Professional Psychology Research and Practice, 28 (1), 44-49.

Schoenwald, S., Halliday-Boykins, C.A., \& Henggler, S.W. (2003). Client-level predictors of adherence to MST in community service settings. Family Process, 42, 345-359.

Schoenwald, S., Ward, D, Henggeler, S.W., Rowland, M. (2000). Multisystemic therapy vs. hospitalization for crisis stabilization of youth: placement outcomes 4 months postreferral. Mental Health Service Resource, 2 (3), 3-12.

Schumacher, J.A., Slep, A.M., Heyman, R.E. (2001). Risk factors for child neglect. Aggression and Violent Behavior, 6 (2-3), 231-254.

Staal, M.A, \& King, R.E. (2000). Managing a multiple relationship environment: the ethics of military psychology. Professional Psychology: Research and Practice, 31 (6), 698-705.

Stern, S.B. (1999). Challenges to family engagement: what can multisystemic therapy teach family therapists? Family Process, 38, 281-286.

Stockman, A.F. (1990). Dual relationships in rural mental health practice: an ethical dilemma. Journal of Rural Community Psychology, 11 (2), 31-45.

Taube, D.O., Elwork, A. (1990). Researching the effects of confidentiality law on patient's self-disclosures. Professional Psychology: Research and Practice, 21, 71-75.

Toffalo, D.A. (2000). An investigation of treatment integrity and outcomes in wraparound services. Journal of Child and Family Studies, 9(3), 351-361.

Weiner, J. \& Boss, P. (1985). Exploring gender bias against women: Ethics for marriage and family therapy. Counseling \& Values, 30(1), 9-23.

Woody, R.H. (1998). Defending against legal complaints. In G.P. Koocher, J.C. Norcross \& S.S. Hill, III. (Eds.), Psychologist's desk reference (pp. 437-442). New York: Oxford University Press.

Zadik, Y. Z. (1993). Breaking confidentiality survey. Medicine and Law, 12, 257-262.

Zur, O. (2001). Out-of-office experience. The Independent Practitioner, 21 (2). 96-100 


\section{APPENDIX A}

\section{Survey Instrument}

\section{PART I}

What is your current age?

$\square 21-25$

$\square 26-30$

$\square 31-35$

$\square 36-40$

$\square 41-45$

$\square 46-50$

$\square 51-55$

$\square 56-60$

$\square 61-65$

$\square 65+$

What is your gender? (check box)

$\square$ Male

$\square$ Female

What is your race? (check box)

$\square$ African American

$\square$ Asian

$\square$ Caucasian

$\square$ Hispanic/Latino

$\square$ Pacific Islander

$\square$ American Indian/ Alaskan Native

$\square$ Other:

What is the highest level of education you've completed? (check box)

$\square$ Master's Degree

$\square$ Doctoral Degree

口Other:

For the highest level of education you've completed, what is your degree in? (check box)

$\square$ Social Work

$\square$ Education

$\square$ Counseling

$\square$ Psychology

$\square \mathrm{I} / \mathrm{O}$ Psychology

$\square$ School Psychology

$\square$ Experimental Psychology

$\square$ Clinical Psychology

$\square$ Other: 
What is your primary theoretical Orientation? (check box)

$\square$ Psychodynamic

$\square$ Psychoanalytic

$\square$ Behavioral

$\square$ Cognitive-Behavioral

$\square$ Humanistic

$\square$ Gestalt

$\square$ Interpersonal

$\square$ Integrated

$\square$ Other:

Are you currently employed part-time or full-time? (check box)

$\square$ Part-Time

$\square$ Full Time

How many years have you worked in your current position?

$\square$ Less than 1 year

$\square 1$ year to 2 years

$\square 2$ years to 5 years

$\square$ More than 5 years, but less than 10 years

$\square$ More than 10 years, but less than 20 years

$\square 20$ years or more

How many years total have you worked as a therapist?

$\square$ Less than 1 year

$\square$ 1 year to 2 years

$\square 2$ years to 5 years

$\square$ More than 5 years, but less than 10 years

$\square$ More than 10 years, but less than 20 years

$\square 20$ years or more

In your current position, which of the following best describes the therapy setting you work in most? (check box)

$\square$ In-home

$\square$ Office-Based

$\square$ Mixed

If mixed, what $\%$ of time out of $100 \%$ is dedicated to each setting?

In-home \% _ _ Office Based \%

Are you currently licensed by the state that your practice in? (check box)

$\square$ Yes

$\square$ No

Have you ever had an academic course that focused on ethics as they pertain to your field of work while obtaining your degree? (check box)

$\square$ Yes

$\square$ No 


\section{PART II}

Working in therapy requires a person to wear many hats. Part of the job involves directly working with clients and their families while another part requires documentation and treatment planning. Below is a list of some things that therapists run into during the course of their job. For each, please indicate (by checking the appropriate box) how often you believe other therapists in your position (i.e., in-home, office-based, mixed) do each thing over the course of a year. In other words, please provide your best guess as to how often you believe others besides yourself are doing any of the following.

How often would you say that other therapists in your position (i.e., in-home, office-based, mixed) are doing the following in the course of one calendar year (12 months)?

1. Accepting an invitation to a client's special event (e.g., birthday party, baseball game, dance recital, etc.)

$\square$ Weekly $\quad \square$ Monthly $\quad \square$ Several times a year $\quad \square$ Once a year $\quad \square$ Never

2. Providing individual therapy to a relative, friend, or significant other of an ongoing client or their immediate family (e.g. a person not originally identified as integral to the client's treatment, yet is still seen separately for any length of time regarding unrelated therapeutic issues).

$\square$ Weekly $\quad \square$ Monthly $\quad \square$ Several times a year $\quad \square$ Once a year $\quad \square$ Never

3. Having a stranger ask questions about the therapist's relationship with a client or their immediate family when in a public venue (e.g., while shopping, dining, etc.)

$\square$ Weekly $\quad \square$ Monthly $\quad \square$ Several times a year $\quad \square$ Once a year $\quad \square$ Never

4. Accepting a service or product as payment for therapy (e.g., wholesale items, car repair, etc.)

$\square$ Weekly $\quad \square$ Monthly $\quad \square$ Several times a year $\quad \square$ Once a year $\quad \square$ Never

5. Becoming privy to direct evidence that a client and/or their immediate family members are involved in active criminal activity (e.g., assault, vandalism, theft, fire-setting, etc.)

$\square$ Weekly $\quad \square$ Monthly $\quad \square$ Several times a year $\quad \square$ Once a year $\quad \square$ Never

6. Disclosing sensational aspects about a client or their immediate family members to friends and colleagues that have no role in the case

$\square$ Weekly $\quad \square$ Monthly $\quad \square$ Several times a year $\quad \square$ Once a year $\quad \square$ Never

7. Calling anonymously to child protective services, the police department, or animal control to report negligent or criminal activity engaged in by the client or their immediate family members

口Weekly $\quad \square$ Monthly $\quad \square$ Several times a year $\quad \square$ Once a year $\quad \square$ Never

8. Disclosing details of current personal stress to a client or their immediate family (e.g., car breakdowns, employment issues, relationship problems, health issues, etc.)

口Weekly $\quad \square$ Monthly $\quad \square$ Several times a year $\quad \square$ Once a year $\quad \square$ Never 
9. Employing a client or their immediate family members (e.g. wash car, rake leaves, clerical or custodial work, etc.)

$\square$ Weekly $\quad \square$ Monthly $\quad \square$ Several times a year $\quad \square$ Once a year $\quad \square$ Never

10. Having difficulties in maintaining the therapeutic environment due to intrusions by others (friends, neighbors, other family members) that are not directly involved in the therapy, but who monopolize time
$\square$ Weekly
$\square$ Monthly
$\square$ Several times a year
$\square$ Once a year
$\square$ Never

11. Becoming privy to direct evidence that a client or their immediate family member's are involved in illegal drug sales, which operate from the client's home address
Weekly
Monthly
$\square$ Several times a year
$\square$ Once a year
$\square$ Never

12. Buying goods or services from a client or their immediate family members (e.g., Girl Scout cookies, church raffle tickets, cosmetic supplies, wholesale items, etc.)
Weekly
$\square$ Monthly
$\square$ Several times a year
$\square$ Once a year
$\square$ Never

13. Inviting a client or their immediate family to a personal party or social event (e.g., Christmas party, graduation ceremony, promotion celebration, etc.)

$\square$ Weekly $\quad \square$ Monthly $\square$ Several times a year $\quad \square$ Once a year $\quad \square$ Never

14. Breaking confidentiality if the client is engaged in sexual activity and is under the age of 18 (e.g., reporting to a parent, caretaker, pastor, mentor, etc.)

$\square$ Weekly $\quad \square$ Monthly $\quad \square$ Several times a year $\quad \square$ Once a year $\quad \square$ Never

15. Making exceptions for certain clients and their immediate family members such as providing special scheduling times, allowing for extra unbilled therapy time, or allowing greater accessibility during off-hours

$\square$ Weekly $\quad \square$ Monthly $\quad \square$ Several times a year $\quad \square$ Once a year $\quad \square$ Never

16. Driving a client or their immediate family member on an errand that does not have any relation to their therapeutic goals (e.g., to the grocery store, to an extra-curricular activity, to a bank to deposit money)

$\square$ Weekly $\quad \square$ Monthly $\quad \square$ Several times a year $\quad \square$ Once a year $\quad \square$ Never

17. Answering questions pertaining to individuals that are outside the bounds of the client and their immediate family that have no direct relation to the current goals (e.g., "My neighbor has been having troubles with her son, do you think it's ADHD?”)

$\square$ Weekly $\quad \square$ Monthly $\quad \square$ Several times a year $\quad \square$ Once a year $\quad \square$ Never

18. Engaging in hugs and other forms of non-sexual touching with clients and their immediate family members
$\square$ Weekly
$\square$ Monthly
$\square$ Several times a year
$\square$ Once a year
$\square$ Never

19. Becoming privy to direct evidence that a client or their immediate family members are being cruel to animals or using animals in an otherwise illegal manner (e.g., dog fights)

पWeekly $\quad \square$ Monthly $\quad \square$ Several times a year $\quad \square$ Once a year $\quad \square$ Never 
20. Breaking confidentiality if the client is using drugs and/or alcohol and is under the age of 18 (e.g., reporting to parent, caretaker, pastor, probation officer, etc.)

$\square$ Weekly $\quad \square$ Monthly $\quad \square$ Several times a year $\quad \square$ Once a year $\quad \square$ Never

21. Offering to perform free intellectual testing or a free diagnostic assessment for family members or friends of the client or client's family

$\square$ Weekly $\quad \square$ Monthly $\quad \square$ Several times a year $\quad \square$ Once a year $\quad \square$ Never

22. Modifying a diagnosis so that a client may obtain more intensive services or an extended amount of sessions

$\square$ Weekly $\quad \square$ Monthly $\quad \square$ Several times a year $\quad \square$ Once a year $\quad \square$ Never

23. Completing paperwork of a sensitive clinical nature in a public location (e.g., coffee house, restaurant, classroom, etc.)

Weekly $\quad \square$ Monthly $\square$ Several times a year $\quad \square$ Once a year $\quad \square$ Never

24. Becoming privy to direct evidence that a child or adolescent client is being physically abused

$\square$ Weekly $\quad \square$ Monthly $\quad \square$ Several times a year $\quad \square$ Once a year $\quad \square$ Never

25. Becoming privy to direct evidence that a child or adolescent client is being sexually abused

$\square$ Weekly $\quad \square$ Monthly $\quad \square$ Several times a year $\quad \square$ Once a year $\quad \square$ Never

26. Answering questions pertaining to non-therapeutic issues outside of the therapist's direct role (e.g., “Could you tell me how to set my VCR?”; “Could you give me your opinion on whether I should call someone to check out my water heater?”)

$\square$ Weekly $\quad \square$ Monthly $\quad \square$ Several times a year $\quad \square$ Once a year $\quad \square$ Never

27. Intervening in academic, therapeutic, or vocational matters with a family member that is not the specified client (e.g., assisting an Uncle in finding a local AA meeting, attending a disciplinarian meeting for an older sibling, etc.)

口Weekly $\quad \square$ Monthly $\quad \square$ Several times a year $\quad \square$ Once a year $\quad \square$ Never

28. Leaving paperwork of a sensitive clinical nature exposed so that others in the vicinity can obtain a client's confidential information (e.g., case notes spread across the front seat of a car, multiple client's treatment plans in one binder, etc.)

$\square$ Weekly $\quad \square$ Monthly $\quad \square$ Several times a year $\quad \square$ Once a year $\quad \square$ Never

29. Becoming privy to direct evidence that a client's immediate family member (sibling, parent, livein relative) is being physically or sexually abused

$\square$ Weekly $\quad \square$ Monthly $\quad \square$ Several times a year $\quad \square$ Once a year $\quad \square$ Never

30. Becoming privy to direct evidence that a client or underage member of the client's family is engaged in a sexual relationship with an adult that is more than three years their senior (e.g., a 16 year-old engaging in sexual contact with a 19 year old)

$\square$ Weekly $\quad \square$ Monthly $\quad \square$ Several times a year $\quad \square$ Once a year $\quad \square$ Never 


\section{PART III}

How often do you personally ...

\section{Receive group supervision from a clinical supervisor?}

$\square$ More than once a week

$\square$ Once a week

$\square$ Every other week

$\square$ Monthly

$\square$ Every other month

$\square$ Quarterly/4 times a year

$\square$ Once or twice a year

$\square$ Never

\section{Receive individual supervision from a clinical supervisor?}

$\square$ More than once a week

$\square$ Once a week

$\square$ Every other week

$\square$ Monthly

$\square$ Every other month

$\square$ Quarterly/4 times a year

$\square$ Once or twice a year

$\square$ Never

3. Receive direct observation by a supervisor during a therapy session OR through a review of an audio or video tape of a therapy session?

$\square$ More than once a week

$\square$ Once a week

$\square$ Every other week

$\square$ Monthly

$\square$ Every other month

$\square$ Quarterly/4 times a year

$\square$ Once or twice a year

$\square$ Never

\section{Receive clinical consultation from a coworker or colleague in the field?}

$\square$ More than once a week

$\square$ Once a week

$\square$ Every other week

$\square$ Monthly

$\square$ Every other month

$\square$ Quarterly/4 times a year

$\square$ Once or twice a year

$\square$ Never

5. Encounter what you consider to be unethical behaviors by your coworkers who are in the same position as yourself (e.g., either in-home therapy, office-based therapy, or mixed)?

$\square$ More than once a week

$\square$ Once a week

$\square$ Every other week 
$\square$ Monthly

$\square$ Every other month

$\square$ Quarterly/4 times a year

$\square$ Once or twice a year

$\square$ Never

6. Report these unethical behaviors to your clinical supervisor?

$\square$ More than once a week

$\square$ Once a week

$\square$ Every other week

$\square$ Monthly

$\square$ Every other month

$\square$ Quarterly/4 times a year

$\square$ Once or twice a year

$\square$ Never

7. Intentionally keep information from a direct clinical supervisor due to concerns that they would not understand the differences inherent in the setting (e.g., supervisor operates from office-setting, therapist works within the home setting or vice-versa)?

$\square$ More than once a week

$\square$ Once a week

$\square$ Every other week

$\square$ Monthly

$\square$ Every other month

$\square$ Quarterly/4 times a year

$\square$ Once or twice a year

$\square$ Never

8. Ignore direct advice given by a direct clinical supervisor involving client care or therapeutic interventions that should be performed?

$\square$ More than once a week

$\square$ Once a week

$\square$ Every other week

$\square$ Monthly

$\square$ Every other month

$\square$ Quarterly/4 times a year

$\square$ Once or twice a year

$\square$ Never

9. Seek advice on issues pertaining to mandatory reporting laws in regards to described child abuse and/or neglect?

$\square$ More than once a week

$\square$ Once a week

$\square$ Every other week

$\square$ Monthly

$\square$ Every other month

$\square$ Quarterly/4 times a year

$\square$ Once or twice a year

$\square$ Never 
10. Seek advice on issues pertaining to mandatory reporting laws in regards to observed child abuse and neglect?

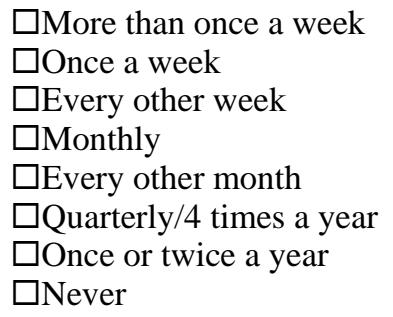

11. Worry that you have committed ethical violations that could negatively affect the therapeutic success of your client?

$\square$ More than once a week

$\square$ Once a week

$\square$ Every other week

$\square$ Monthly

$\square$ Every other month

$\square$ Quarterly/4 times a year

$\square$ Once or twice a year

$\square$ Never

12. Worry that you have committed ethical violations that could negatively affect your licensure (if applicable) or overall practice as a therapist?

$\square$ More than once a week

$\square$ Once a week

$\square$ Every other week

$\square$ Monthly

$\square$ Every other month

$\square$ Quarterly/4 times a year

$\square$ Once or twice a year

$\square$ Never

13. Leave supervision knowing how to carry out recommended actions?

$\square$ More than once a week

$\square$ Once a week

$\square$ Every other week

$\square$ Monthly

$\square$ Every other month

$\square$ Quarterly/4 times a year

$\square$ Once or twice a year

$\square$ Never

\section{Thank-you for completing this survey! Please place your completed survey in the enclosed self-addressed stamped envelope and drop it in the nearest mailbox.}




\section{Appendix B}

Table 1: Demographics

\begin{tabular}{|c|c|c|}
\hline & Frequency & Percent \\
\hline \multicolumn{3}{|l|}{ AGE } \\
\hline $21-25$ & 12 & $12.4 \%$ \\
\hline $26-30$ & 33 & $34.0 \%$ \\
\hline 31-35 & 15 & $15.5 \%$ \\
\hline $36-40$ & 10 & $10.3 \%$ \\
\hline $41-45$ & 9 & $9.3 \%$ \\
\hline $46-50$ & 7 & $7.2 \%$ \\
\hline $51-55$ & 5 & $5.2 \%$ \\
\hline $56-60$ & 4 & $4.1 \%$ \\
\hline $61-65$ & 1 & $1.0 \%$ \\
\hline $65+$ & 1 & $1.0 \%$ \\
\hline \multicolumn{3}{|l|}{ GENDER } \\
\hline Male & 21 & $21.6 \%$ \\
\hline Female & 76 & $78.4 \%$ \\
\hline \multicolumn{3}{|l|}{ RACE/ETHNICITY } \\
\hline African American & 7 & $7.2 \%$ \\
\hline Asian & 1 & $1.0 \%$ \\
\hline Caucasian & 89 & $91.8 \%$ \\
\hline \multicolumn{3}{|c|}{ HIGHEST LEVEL OF EDUCATION } \\
\hline Master’s Degree & 87 & $89.7 \%$ \\
\hline Doctoral Degree & 9 & $9.3 \%$ \\
\hline Other & 1 & $1.0 \%$ \\
\hline
\end{tabular}


Table 1: Demographics (Continued)

Frequency

Percent

DEGREE TYPE

Social Work

21

$21.6 \%$

Education

10

$10.3 \%$

Counseling

25

$25.8 \%$

Counseling Psychology

14

$14.4 \%$

Clinical Psychology

$3.1 \%$

School Psychology

12

$12.4 \%$

Other

12

$12.4 \%$

\section{THEORETICAL ORIENTATION}

Psychodynamic

3

$3.1 \%$

Psychoanalytic

4

$4.1 \%$

Behavioral

16

$16.5 \%$

Cognitive-Behavioral

41

$42.3 \%$

Humanistic

3

$3.1 \%$

Interpersonal

1

Integrated

16

$1.0 \%$

Other

$16.5 \%$

$7.2 \%$

WORK

Part-time

$35.1 \%$

Full-time

\section{YEARS WORKED AS A THERAPIST}

Less than 1 yea

$12.4 \%$

More than 1 year, but less than 2 years

17

$17.5 \%$

More than 2 years, but less than 5 years

28

$28.9 \%$

More than 5 years, but less than 10 years

22

$22.7 \%$

More than 10 years, but less than 20 years

12

$12.4 \%$

20 years of more

6

$6.2 \%$ 
Table 1: Demographics (Continued)

\begin{tabular}{lcc}
\hline & Frequency & Percent \\
CURRENT POSITION & & \\
Home-based & 51 & $52.6 \%$ \\
Office Based & 32 & $33.0 \%$ \\
Mixed & 14 & $14.4 \%$ \\
& & \\
LICENSED & & \\
Yes & 37 & $38.1 \%$ \\
No & 60 & $61.9 \%$ \\
& & \\
ETHICS COURSE & & $81.4 \%$ \\
Yes & 79 & $18.6 \%$ \\
No & 18 &
\end{tabular}


Table 2

Reliability Analysis of Confidentiality Measure

\begin{tabular}{llll}
\hline Questions & Mean & Standard Deviation & Cases \\
\hline Q3 & 1.2174 & 1.1370 & 92 \\
Q6 & 1.7065 & 1.3469 & 92 \\
Q23 & 1.7826 & 1.4206 & 92 \\
Q28 & 1.4565 & 1.3701 & 92 \\
\hline
\end{tabular}

Alpha $=.7258$

Q3 = Having a stranger ask questions about the therapist's relationship with a client or their immediate family when in a public venue (e.g., while shopping, dining, etc.)

Q6 = Disclosing sensational aspects about a client or their immediate family members to friends and colleagues that have no role in the case

Q23 = Completing paperwork of a sensitive clinical nature in a public location (e.g., coffee house, restaurant, classroom, etc.)

Q28 = Leaving paperwork of a sensitive clinical nature exposed so that others in the vicinity can obtain a client's confidential information (e.g., case notes spread across the front seat of a car, multiple client's treatment plans in one binder, etc.) 
Table 3

Reliability Analysis of Role Confusion Measure

\begin{tabular}{lccl}
\hline Questions & Mean & Standard Deviation & Cases \\
\hline Q1 & 1.056 & .8299 & 95 \\
Q8 & 1.7158 & 1.1361 & 95 \\
Q9 & .3579 & .6174 & 95 \\
Q12 & 1.4000 & .9828 & 95 \\
Q13 & .3579 & .6510 & 95 \\
Q15 & 1.6211 & 1.1776 & 95 \\
Q16 & .9158 & 1.1730 & 95 \\
Q18 & 2.0316 & 1.1801 & 95 \\
Q26 & 1.8211 & 1.2461 & 95 \\
\hline
\end{tabular}

Alpha $=.8543$

Q1 = Accepting an invitation to a client's special event (e.g., birthday party, baseball game, dance recital, etc.)

Q8 = Disclosing details of current personal stress to a client or their immediate family (e.g., car breakdowns, employment issues, relationship problems, health issues, etc.)

Q9 = Disclosing details of current personal stress to a client or their immediate family (e.g., car breakdowns, employment issues, relationship problems, health issues, etc.)

Q12 = Buying goods or services from a client or their immediate family members (e.g., Girl Scout cookies, church raffle tickets, cosmetic supplies, wholesale items, etc.)

Q13 = Inviting a client or their immediate family to a personal party or social event (e.g., Christmas party, graduation ceremony, promotion celebration, etc.)

Q15 = Making exceptions for certain clients and their immediate family members such as providing special scheduling times, allowing for extra unbilled therapy time, or allowing greater accessibility during off-hours

Q16 = Driving a client or their immediate family member on an errand that does not have any relation to their therapeutic goals (e.g., to the grocery store, to an extra-curricular activity, to a bank to deposit money)

Q18 = Engaging in hugs and other forms of non-sexual touching with clients and their immediate family members

Q26 = Answering questions pertaining to non-therapeutic issues outside of the therapist's direct role (e.g., "Could you tell me how to set my VCR?”; “Could you give me your opinion on whether I should call someone to check out my water heater 
Table 4

Reliability Analysis of Client Diffusion Measure

\begin{tabular}{llll}
\hline Questions & Mean & Standard Deviation & Cases \\
\hline Q2 & 1.2784 & 1.2889 & 97 \\
Q10 & 1.9278 & 1.2686 & 97 \\
Q17 & 1.4433 & 1.0894 & 97 \\
Q27 & 1.3711 & 1.1117 & 97 \\
\hline
\end{tabular}

Alpha $=.6974$

Q2 = Providing individual therapy to a relative, friend, or significant other of an ongoing client or their immediate family

Q10 = Having difficulties in maintaining the therapeutic environment due to intrusions by others (friends, neighbors, other family members) that are not directly involved in the therapy, but who monopolize time

Q 17 = Answering questions pertaining to individuals that are outside the bounds of the client and their immediate family that have no direct relation to the current goals (e.g., "My neighbor has been having troubles with her son, do you think it's ADHD?")

Q 27 = Intervening in academic, therapeutic, or vocational matters with a family member that is not the specified client (e.g., assisting an Uncle in finding a local AA meeting, attending a disciplinarian meeting for an older sibling, etc.) 
Table 5

Reliability Analysis of Unintentional Witnessing Measure

\begin{tabular}{lccl}
\hline Questions & Mean & Standard Deviation & Cases \\
\hline Q5 & 1.3708 & .9580 & 89 \\
Q7 & 1.3933 & .8741 & 89 \\
Q11 & 1.0787 & .9912 & 89 \\
Q19 & .8652 & .8553 & 89 \\
Q20 & 1.1685 & 1.0251 & 89 \\
Q29 & 1.2584 & .8858 & 89 \\
Q30 & 1.1798 & .8734 & 89 \\
\hline
\end{tabular}

Alpha $=.9099$

Q5 = Becoming privy to direct evidence that a client and/or their immediate family members are involved in active criminal activity (e.g., assault, vandalism, theft, fire-setting, etc.)

Q7 = Calling anonymously to child protective services, the police department, or animal control to report negligent or criminal activity engaged in by the client or their immediate family members

Q 11 = Becoming privy to direct evidence that a client or their immediate family member's are involved in illegal drug sales, which operate from the client's home address

Q 19 = Becoming privy to direct evidence that a client or their immediate family members are being cruel to animals or using animals in an otherwise illegal manner (e.g., dog fights)

Q20 = Breaking confidentiality if the client is using drugs and/or alcohol and is under the age of 18 (e.g., reporting to parent, caretaker, pastor, probation officer, etc.)

Q29 = Becoming privy to direct evidence that a client's immediate family member (sibling, parent, livein relative) is being physically or sexually abused

Q30 = Becoming privy to direct evidence that a client or underage member of the client's family is engaged in a sexual relationship with an adult that is more than three years their senior (e.g., a 16 year-old engaging in sexual contact with a 19 year old) 
Table 6: Hypothesis \#1: Independent Sample Difference of Means Test for Completing an Ethics Course and the Ethical Dimensions

\begin{tabular}{ccccc}
\hline & Mean & SD & $\mathrm{t}$ & Significance \\
$\begin{array}{c}\text { Confidentiality } \\
\text { Yes }\end{array}$ & 5.93 & 4.03 & -1.224 & .224 \\
No & 7.25 & 3.24 & -1.224 & .224 \\
& & & & \\
Role Confusion & & & & .515 \\
Yes & 11.08 & 6.64 & -.653 & .515 \\
No & 12.18 & 4.20 & -.653 & .619 \\
Client Diffusion & & & & .619 \\
Yes & 5.94 & 3.59 & -.499 & .909 \\
No & 6.39 & 2.87 & -.499 & .909 \\
Unintentional Witnessing & & & & \\
Yes & 8.08 & 4.68 & -.114 & -.114 \\
No & 8.22 & 5.39 & &
\end{tabular}


Table 7: Hypothesis \#2: Independent Sample Difference of Means Test for State Licensure and Ethical Dimensions

$\begin{array}{lllll} & \text { Mean } & \text { SD } & \mathrm{t} & \text { Significance } \\ \begin{array}{c}\text { Confidentiality } \\ \text { Yes }\end{array} & 5.58 & 3.77 & -1.139 & .258 \\ \text { No } & 6.53 & 4.00 & -1.139 & .258 \\ \text { Role Confusion } & & & & \\ \text { Yes } & 9.94 & 5.61 & -1.664 & .099 \\ \text { No } & 12.12 & 6.56 & -1.664 & .099 \\ \text { Client Diffusion } & & & & \\ \text { Yes } & 5.32 & 3.72 & -1.571 & .120 \\ \text { No } & 6.45 & 3.24 & -1.571 & .120 \\ \text { Unintentional Witnessing } & & & & .700 \\ \text { Yes } & 7.86 & 5.30 & -.386 & .700 \\ \text { No } & 8.25 & 4.50 & -.386 & \end{array}$


Table 8: Hypothesis \#3: Independent Sample Difference of Means Test for Amount of Structured Supervision and Type of Therapist

Mean SD $\quad t \quad$ Significance

Group Supervision

Home based

3.74

1.69

$-1.151$

.253

Office based

4.22

2.32

$-1.151$

.253

Individual Supervision

Home based

3.64

2.13

$-2.589$

.011

Office based

4.76

1.94

$-2.589$

.011

Encounter unethical behaviors

$\begin{array}{ll}\text { Home based } & 1.95 \\ \text { Office based } & 2.03\end{array}$

2.00

$-.182$

.856

Office based

2.15

$-.182$

.856

Report unethical behaviors

$\begin{array}{lc}\text { Home based } & .93 \\ \text { Office based } & 1.00\end{array}$

1.46

$-.252$

.801

Office based

1.00

1.03

$-.252$

.801

Receive clinical consultation

$\begin{array}{ll}\text { Home based } & -1.11 \\ \text { Office based } & -1.11\end{array}$

.422

$-2.633$

.010

Office based

.418

$-2.633$

.010

Keep information from supervisor

Home based

.53

Office based

.08

1.22

2.184

.031

.28

2.184

.031

Ignore advice given by supervisor

Home based

.94

.021

.983

Office based

.70

.021

.983

Described mandatory report laws

Home based

Office based

1.47

1.95

1.32

$-1.706$

.091

$-1.706$

.091

Observed mandatory report laws

Home based

Office based

1.05

1.00

1.34

.221

.825

.75

.221

.825

Know how to carry-out actions

Home based

3.81

Office based
2.04

1.80
$-1.703$

.092

$-1.703$

.092 
Table 9: Hypothesis \#4: One Way Analysis of Variance Between Years Working as a Therapist and Supervision

$\begin{array}{lllll}\text { N } & \text { Mean } & \text { SD } & \text { F } & \text { Sig }\end{array}$

Group Supervision

$\begin{array}{llllll}(0)<1 \mathrm{yr} & 12 & 3.25 & 2.179 & .687 & .634 \\ (1)>1,<2 \mathrm{yr} & 17 & 3.76 & 2.078 & .687 & .634 \\ (2)>2,<5 \mathrm{yr} & 28 & 4.36 & 1.569 & .687 & .634 \\ (3)>5,<10 \mathrm{yr} & 22 & 4.09 & 1.688 & .687 & .634 \\ (4)>10 \mathrm{yr},<20 & 12 & 3.58 & 2.429 & .687 & .634 \\ (5) 20 \mathrm{yr}+ & 6 & 3.83 & 2.714 & .687 & .634\end{array}$

Individual Supervision

$\begin{array}{llllll}(0)<1 \mathrm{yr} & 12 & 4.33 & 2.188 & .901 & .484 \\ (1)>1,<2 \mathrm{yr} & 17 & 4.12 & 2.176 & .901 & .484 \\ (2)>2,<5 \mathrm{yr} & 28 & 4.32 & 2.019 & .901 & .484 \\ (3)>5,<10 \mathrm{yr} & 22 & 4.27 & 1.778 & .901 & .484 \\ (4)>10 \mathrm{yr},<20 & 12 & 2.92 & 2.539 & .901 & .484 \\ (5) 20 \mathrm{yr}+ & 6 & 3.83 & 2.229 & .901 & .484\end{array}$

Keep Information from Supervisor

$\begin{array}{lrrrrl}(0)<1 \mathrm{yr} & 12 & .17 & .577 & .701 & .624 \\ (1)>1,<2 \mathrm{yr} & 17 & .35 & 1.222 & .701 & .624 \\ (2)>2,<5 \mathrm{yr} & 28 & .57 & 1.230 & .701 & .624 \\ (3)>5,<10 \mathrm{yr} & 22 & .23 & .528 & .701 & .624 \\ (4)>10 \mathrm{yr},<20 & 11 & .09 & .302 & .701 & .624 \\ (5) 20 \mathrm{yr}+ & 6 & .67 & 1.633 & .701 & .624\end{array}$

Know how to carry out actions

$\begin{array}{llllll}(0)<1 \mathrm{yr} & 11 & 4.27 & 1.489 & .589 & .708 \\ (1)>1,<2 \mathrm{yr} & 16 & 4.13 & 2.277 & .589 & .708 \\ (2)>2,<5 \mathrm{yr} & 27 & 4.33 & 1.922 & .589 & .708 \\ (3)>5,<10 \mathrm{yr} & 22 & 4.36 & 1.866 & .589 & .708 \\ (4)>10 \mathrm{yr},<20 & 10 & 3.40 & 2.221 & .589 & .708 \\ (5) 20 \mathrm{yr}+ & 6 & 3.33 & 2.338 & .589 & .708\end{array}$


Table 10: Hypothesis \#5: Independent Difference of Means Test Between Type of Therapist and Ethical Dimensions

$\begin{array}{ccccc} & \text { Mean } & \text { SD } & \mathrm{t} & \text { Significance } \\ \text { Confidentiality } & & & & .003 \\ \text { Home based } & 7.18 & 3.90 & 3.010 & .003 \\ \text { Office based } & 4.73 & 3.38 & 3.010 & \\ & & & & .040 \\ \text { Role Confusion } & 12.40 & 6.79 & 2.086 & .040 \\ \text { Home based } & 9.67 & 5.01 & 2.086 & \\ \text { Office based } & & & & .058 \\ & & & & .058 \\ \text { Client Diffusion } & 6.62 & 3.42 & 1.919 & \\ \text { Home based } & 5.24 & 3.40 & 1.919 & .458 \\ \text { Office based } & & & & .748 \\ \text { Unintentional Witnessing } & & 5.23 & & \\ \text { Home based } & 7.80 & 4.17 & -.745 & \\ \text { Office based } & 8.57 & & & \\ \end{array}$


Table 11: Hypothesis \# 5: Independent Difference of Means Tests Between Type of Therapist and Demographics

Mean SD $\quad t \quad$ Significance

Age

$\begin{array}{lllll}\text { Home based } & 2.26 & 2.181 & -.945 & .347 \\ \text { Office based } & 2.68 & 1.959 & -.945 & .347\end{array}$

Gender

Home based

.81

.395

$.619 \quad .537$

Office based

.76

.435

.619

.537

Race

Home based

.184

.523

$-.448$

.655

Office based

.189

.458

$-.448$

.655

Level of Education

Home based

.05

.223

$-1.804$

.074

Office based

.16

.374

$-1.804$

.074

Theoretical Orientation

Home based

3.66

2.103

$-.707$

.481

Office based

4.00

2.427

$-.707$

.481

Years at Position

Home based

1.66

1.132

$-.814$

.418

Office based

1.86

1.357

$-.814$

.418

Years as Therapist

Home based

2.14

1.304

$-1.211$

.229

Office based

2.49

1.465

$-1.211$

.229

Currently Licensed

Home based

.74

.442

3.440

.001

Office based

.41

.498

3.440

.001

Ethics course

Home based

.19

.395

.006

.996

Office based

.19

.397

.006

.996 
Table 12: Hypothesis \# 5: Ordinary Least Squares Regression. Dependent Variable = Confidentiality Scale (Questions 3,6,23,28).

\begin{tabular}{lllll}
\hline & $\mathrm{b}$ & $\mathrm{SE}$ & $\mathrm{t}$ & $\mathrm{S}$ \\
Constant & 6.943 & .807 & 8.607 & .000 \\
Position Type & & & & \\
& -2.330 & .879 & -2.652 & .010 \\
Current Licensure & .316 & .864 & .365 & .716 \\
\hline $\mathrm{F}=4.552, \mathrm{p}=.013$ & & & \\
$\mathrm{R} 2=.095$ & & &
\end{tabular}

Table 13: Hypothesis \# 5: Ordinary Least Squares Regression. Dependent Variable = Role Confusion Scale (Questions 1, 8, 9, 12, 13, 15, 16, 18, 26).

\begin{tabular}{lllll}
\hline & $\mathrm{b}$ & $\mathrm{SE}$ & $\mathrm{t}$ & $\mathrm{S}$ \\
Constant & 11.249 & 1.309 & 8.593 & .000 \\
Position Type & -2.192 & 1.397 & -1.569 & .120 \\
Current Licensure & 1.567 & 1.390 & 1.127 & .263 \\
\hline $\mathrm{F}=2.816, \mathrm{p}=.065$ & & & \\
$\mathrm{R} 2=.059$ & & & \\
& & & \\
\end{tabular}


Table 14: Hypothesis \# 5: Ordinary Least Squares Regression. Dependent Variable = Client Diffusion (Questions 2, 10, 17, 27).

\begin{tabular}{lllll}
\hline & $\mathrm{b}$ & $\mathrm{SE}$ & $\mathrm{t}$ & $\mathrm{S}$ \\
Constant & 5.967 & .720 & 8.291 & .000 \\
Position Type & & & & \\
& -1.081 & .761 & -1.421 & .159 \\
Current Licensure & .881 & .761 & & \\
\hline $\mathrm{F}=2.519, \mathrm{p}=.086$ & & & & .250 \\
$\mathrm{R} 2=.052$ & & &
\end{tabular}

Table 15: Hypothesis \# 5: Ordinary Least Squares Regression. Dependent Variable = Unintentional Witnessing (Questions 5, 7, 11, 19, 20, 29, 30).

\begin{tabular}{lllll}
\hline & $\mathrm{b}$ & $\mathrm{SE}$ & $\mathrm{t}$ & $\mathrm{S}$ \\
Constant & 7.234 & 1.050 & 6.891 & .000 \\
& & & & \\
Position Type & 1.025 & 1.096 & .936 & .352 \\
& & & & \\
Current Licensure & .759 & 1.101 & .689 & .492 \\
\hline
\end{tabular}

$\mathrm{F}=.514, \mathrm{p}=.600$

$\mathrm{R} 2=.011$ 


\section{Appendix C}

186 Penn Lear Dr., Monroeville, PA 15146

E-mail: redodin@adelphia.net

Phone \#: 412-607-3393

\section{Joseph M. Roberts, L.S.W.}

\section{EDUCATION}

8/02- Present

$8 / 97-5 / 99$

8/90- 5/94

\author{
West Virginia University \\ Doctoral Candidate Counseling Psychology \\ University of Nebraska at Omaha Omaha, NE \\ Master's of Social Work \\ University of Evansville Evansville, IN \\ B. A. in Creative Writing \\ Minor in English Literature
}

OCCUPATIONAL EXPERIENCE

2006-present

Carlow University

Pittsburgh, PA

Assistant Professor

- $\quad$ Teach 3 graduate courses in Counseling each semester

- Assist with the continued development of the Psy.D. program in Counseling Psychology

- $\quad$ Research topics important to the continued development of the field of Counseling Psychology.

\section{APA-Approved Pre-Doctoral Internship}

- Maintained a short-term (9-session) caseload of 7 clients from diverse backgrounds.

- $\quad$ Co-led both an Anxiety Disorders group and a Graduate Level Process Group.

- $\quad$ Performed 4 complete diagnostic assessment batteries (WAIS, MMPI-II, TAT, Bender VMG, etc.) on specified clients.

- $\quad$ Supervised Master's level practicum students in their clinical work at CAPS.

- Maintained at least 1 long-term client who fits a LGBT, Multicultural, or Student Athlete criteria.

- Administered direct crisis intervention as warranted.

- Developed the Fraternal Integrity Alliance, a comprehensive program that addresses the problems of sexual assault on Penn State's campus by challenging the fraternity system to become more active in self-monitoring.

- Attended weekly seminars of a variety of topics such as Group Therapy, Crisis Intervention, Multicultural Therapy, Brief Therapy and Research.

2004-2005 Carnegie Mellon University

Pittsburgh, PA

\section{Doctoral Practicum Student}

a Maintain a caseload of 5-7 individual college-attending clients.

a Utilize appropriate therapeutic modalities within a psychodynamic framework.

u Understand the concepts and function of brief therapy models.

- Attend case conferences and present to supervisory group twice a semester.

2003-present Family Psychological Consultants

Outpatient Therapist and Psychological Evaluator

Kittanning, PA Practicum Student until 5-20-04

- Maintain a caseload of 8-10 individual clients ranging in age from 9-57 years old.

ㄴ Utilize appropriate therapeutic modalities within a managed care framework. 
- Perform diagnostic overview and create viable treatment plans.

a Perform 1-2 integrated psychological reports per week for children involved in the BHRS (Wraparound) system.

- Be familiar with and utilize assessment instruments such as the MMPI-A, MMPI-2, Beck Depression Inventory, Child Behavior Checklist, Conners' Rating Forms, and ADDES-2, as well as a variety of projective tests.

2003-present Carlow University Undergraduate Course Instructor

Pittsburgh, PA

口 Prepare and implement curriculum for Abnormal Psychology during spring 2005.

a Prepare and implement curriculum for Child Psychology (PY 205) during fall 2003 and summer 2004 courses.

- Maintain and teach classroom of 20-25 students.

2000-2004 Turtle Creek Valley MH/MR, Inc

Homestead, PA

Mobile Therapist and Outpatient Therapist

a Maintained a caseload of 8-10 client families.

- Operated within the West Mifflin School System and helped identify potential clients.

- Performed diagnostic overviews and created viable treatment plans.

- Assessed drug and alcohol counseling needs through the use of SASSI-2 instrument

- Identified client strengths and utilized therapeutic modalities such as REBT, structural family therapy, and Interpersonal therapy to assist client in attaining set goals.

1997-2000 Action Pact Youth at Risk Programs: CFB\&G Omaha, NE Director of Adolescent Programs

a Designed and implemented a six-module after-school curriculum for at-risk youth from divergent social, cultural and economic backgrounds.

- Counseled 200+ children between the ages of 10-18 in academics, violence prevention, teen pregnancy, vocational planning, and overall mental health issues.

- Designed and created a $150 \mathrm{pg}$. curriculum manual that targets at-risk adolescents.

a Performed $100+$ home visits in high-risk neighborhoods in a variety of cultural settings.

- Collected over $\$ 90,000$ for programs through fundraising and grant-writing initiatives.

- Increased attendance in after-school programs by more than $500 \%$.

- Evaluated outcome measures across all agency programs.

a Budgeted and tracked all financial needs within the programs in my care.

a Coordinated in-house training for new employees.

- Supervised 6 youth counselors in the field and was a senior member of programming team.

1998-1999 Child Saving Institute Omaha, NE

Family Therapist (Master's Practicum)

- Utilized structural family therapy and cognitive behavioral therapy modalities for in-home therapy of children aged 9-12 years old.

Directed several court-mandated parenting classes.

- Maintained a caseload of 11 families and coordinated all of their resource and therapy needs.

口 Collaborated with 7 different schools in the Omaha area.

1997-1998 Community Alliance

Residential Support Specialist

Omaha, NE

․ Developed in-house support groups for those clients afflicted with schizophrenia.

- Utilized cognitive behavior therapy in working with clients afflicted by delusions and/or hallucinations.

- Created personalized therapeutic plans for mentally ill clients to assist with daily living.

口 Assisted with symptom maintenance and medication distribution.

1995-1997 Dungarvin, Inc.

\section{Chief Residential Manager}

St. Paul, MN

口 Supervised a staff of 8 individuals.

a Coordinated all resources within the household including finances and medical treatment. 
- Designed and implemented all personal achievement plans for the mentally disabled clients.

口 Utilized behavioral interventions to reduce residents' violent behaviors by more than 75\% in 6 months.

\section{PROFESSIONAL AFFILIATION}

2002-present American Psychological Association student affiliate

2001-present Licensed Social Worker in the state of Pennsylvania

1999 University of Nebraska at Omaha Practicum Board Student Committee Member

\section{AWARDS AND HONORS}

2000 Recipient of the Ten Outstanding Young Omahans Award presented by the Omaha Chamber of Commerce and the Omaha Jaycees.

1999 Nominee for the 6 Who Share Community Volunteer Award.

1999 Recipient of the Barbara M. Veach Memorial Scholarship for Academic Excellence.

\section{VOLUNTEER SERVICE}

1998-2000 Youth Mentor for Just You and Me Program through Child Saving Institute

1999.2000 Social Work Advisor for Law Office of Susan Koenig, J.D.

1996.1997 Court Advocate for Minneapolis Domestic Abuse Center

\section{SPEAKING and TRAINING EXPERIENCE}

口 2002 Turtle Creek Valley MH/MR, Inc.

Pittsburgh, PA

Trainer

Practical Uses of Cognitive Therapy for TSS Workers.

口 $2000 \quad$ Sun Dawgs Summer Program Omaha, NE

\section{City Trainer}

The Ten Cardinal Rules of Successful Role Modeling with Children Ages 6-14.

- 1999, 2000 Camp Fire Boys and Girls of the Midlands Omaha, NE

Guest Lecturer

Understanding Cultural Diversity and Child Abuse Prevention

1999 Youth Symposium on Violence Omaha, NE

Guest Lecturer

The Challenge of Adolescent After-School Programming and Preventative Violence Education

- 1998 Child Saving Institute Omaha, NE

Instructor

Court Mandated Parenting Class

1998 Child Saving Institute Family-Therapy Division Omaha, NE

Guest Lecturer

The Positive Aspects of In-Home Therapy When Working with Gang-Affiliated Youth

\section{GRANTS OBTAINED}

ㅁ 2002

口 2000

口 2000

口 2000

1999

1999

1999

ㅁ 1999

1998
Target Community Grant

Lozier Foundation Grant

Nebraska Child Abuse Prevention Fund

Teaching Tolerance Grant

Countryside Church Grant

Nebraska Child Abuse Prevention Fund

Lozier Foundation Grant

Mutual of Omaha ( $2^{\text {nd }}$ Author)

Nebraska Child Abuse Prevention
$\$ 5,000$

$\$ 33,760$

$\$ 3,750$

$\$ 1,000$

$\$ 2,000$

$\$ 5,000$

$\$ 39,000$

$\$ 5,000$

$\$ 4,000$ 